\title{
2-(Trimethylsilyl)ethanesulfonyl (or SES) Group in Amine Protection and Activation
}

\author{
Patrice Ribière, Valérie Declerck, Jean Martinez, and Frédéric Lamaty* \\ Laboratoire des Aminoacides, Peptides et Protéines (LAPP), CNRS-Universités Montpellier 1 et 2, Place Eugène Bataillon, \\ 34095 Montpellier Cedex 5, France
}

Received July 25, 2005

\section{Contents}

1. Introduction

2249

2. SES-Cl in Synthesis

2.1. Synthesis of Sulfonyl Chloride

2250

2.2. Protection of Amines

3. Direct Introduction of 2-(Trimethylsilyl)ethanesulfonamide in Synthesis

3.1. Conversion of an Alcohol into a SES-Protected Amine

3.2. Reactions on 2-(Trimethylsilyl)ethanesulfonylimines

3.2.1. Formation of 2-(Trimethylsilyl)ethanesulfonylimines

3.2.2. Reduction

3.2.3. Nucleophilic Addition

3.2.4. Cycloadditions

3.2.5. Electrocyclization Reactions

3.2.6. Aziridination Reaction

3.2.7. Aza-Baylis-Hillman Reaction

3. 3. (N-SES-imino) Phenyliodinane or $S E S N=I P h$ Reagent

3.3.1. Synthesis of SES Aziridines

3.3.2. Synthesis of SES Sulfoximines

3.4. Sulfonamidoglycosylation

3.4.1. SES- $\mathrm{NH}_{2} / \mathrm{l}(\text { sym-coll })_{2} \mathrm{ClO}_{4}$

3.4.2. SES- $-\mathrm{NBr}_{2}$

3.5. Di-SES-Sulfodiimide

3.6. $\mathrm{SESN}_{3}$

4. SES as an Activating Group

4.1. N-Alkylations

4.2. Nucleophilic Additions

4.3. Mitsunobu Reactions

4.4. Acylation Reactions

5. Limitations of SES Protection

6. Deprotection of the SES Group

6.1. Fluoride Source/Deprotection Conditions

6.2. Orthogonality

6.3. Nonorthogonality

6.4. Problems Occurring during the Deprotection

6.4.1. Dehydrodesulfination/Aromatization

6.4.2. Primary Amine

6.5. "One-Pot" Deprotection and Electrophile Addition

\footnotetext{
* To whom correspondence should be addressed. E-mail: frederic.lamaty@
} univ-montp2.fr.
7. SES Protection on Polymeric Support 2266

8. Conclusion 2268

9. Abbreviations 2268

10. References 2268

\section{Introduction}

Several fields in organic chemistry, such as peptide, nucleoside, or combinatorial synthesis, require easily accessible amine protecting groups which are stable under a broad range of reaction conditions and are both easily and selectively cleavable. Sulfonamides are among the most stable amine protecting groups under a wide range of conditions, but they usually require drastic cleavage conditions which are generally not compatible with highly functionalized, sensitive substrates. In addition to the common Tosyl group, other sulfonamides have been developed with the aim of easy deprotection: nosyl, brosyl, tertbutylsulfonyl (Bus), etc. In the same manner, in 1986 Weinreb developed the 2-(trimethylsilyl)ethanesulfonyl (or 2-(trimethylsilyl)ethylsulfonyl) group, abbreviated as SES. ${ }^{1-5}$ This sulfonyl protection is removed under mild conditions using fluoride ions (eq 1). Indeed, attack of the fluoride ions on the silicon atom leads to a $\beta$-elimination which releases the deprotected amine and volatile products: fluorotrimethylsilane, ethylene, and sulfur dioxide.

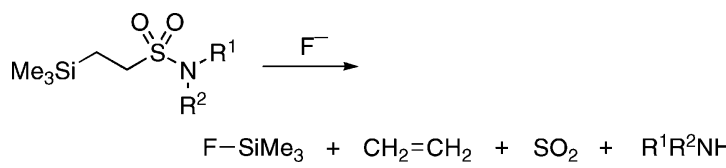

The SES protecting group is employed as an alternative to a tosyl sulfonamide, which is usually troublesome to deprotect. However, while the SES group was initially used as a simple protection for amines, over the years several reagents or reactions have been developed to introduce directly an amine such as 2-(trimethylsilyl)ethanesulfonamide into a molecule (Scheme 1).

The first part of this review will thus present the introduction of the SES protecting group on a molecule bearing a nitrogen in its structure, whereas the second part details the various methods to introduce directly the 2-(trimethylsilyl)ethanesulfonamide into a substrate. Thereafter, the various uses of 2-(trimethylsilyl)ethanesulfonamides in synthesis will be described, followed by a short presentation of the SES protection limitations. To finish, deprotection of the SES 
Scheme 1
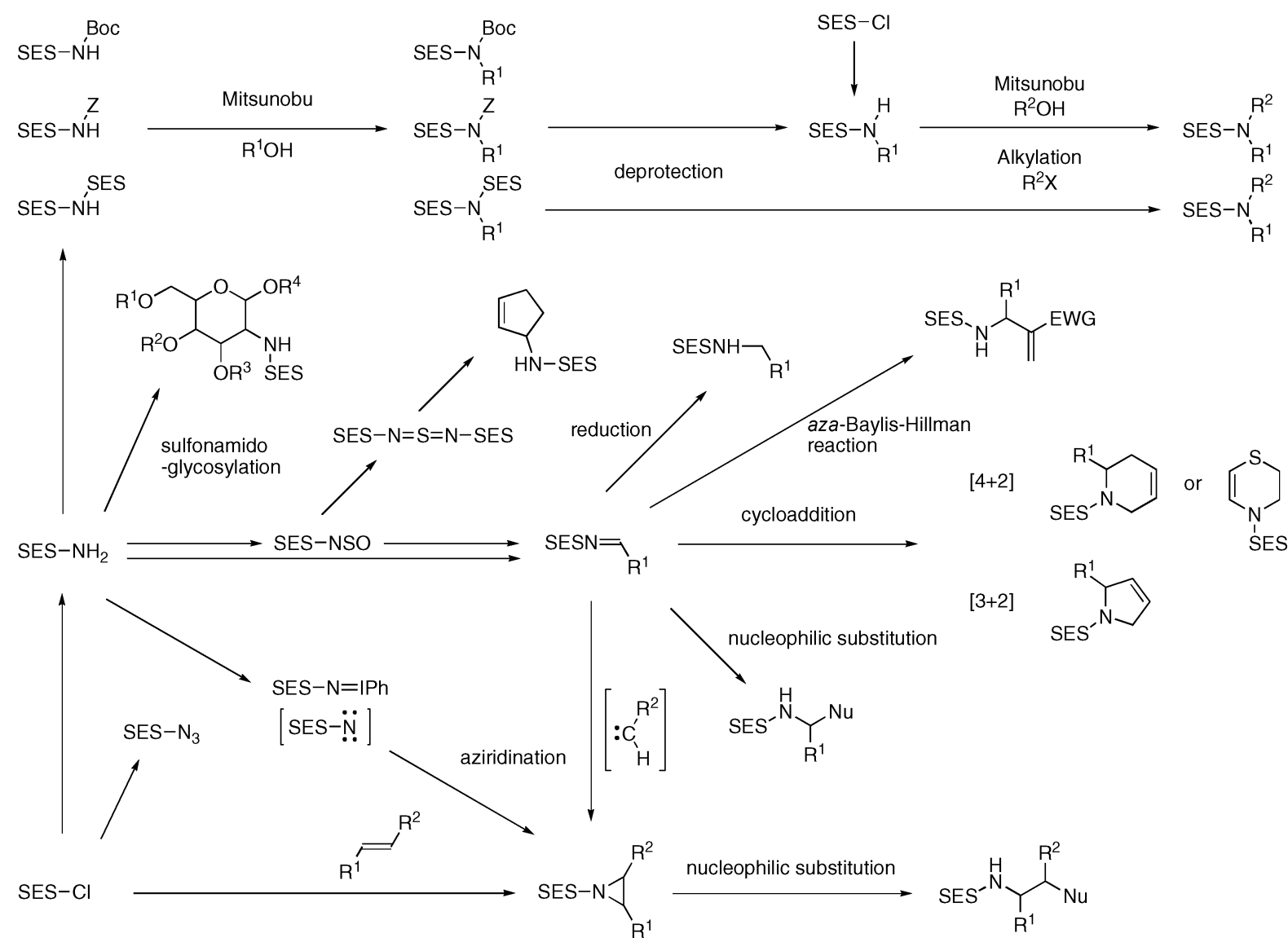

group will be studied before presenting polymer-supported SES groups.

\section{SES-Cl in Synthesis}

\subsection{Synthesis of Sulfonyl Chloride}

\section{Scheme $2^{a}$}

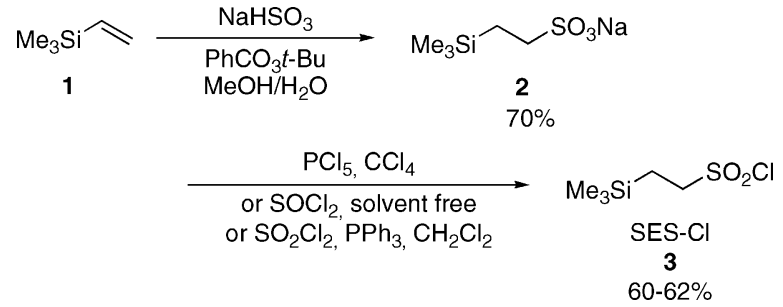

${ }^{a}$ Reprinted with permission from refs 1, 6, and 7. Copyright 1986, 1992 Elsevier and 1998 Organic Syntheses, Inc., respectively.

The free-radical addition ${ }^{1}$ (Scheme 2) of sodium bisulfite on the double bond of vinyltrimethylsilane $\mathbf{1}$ catalyzed by tert-butyl perbenzoate provided the sulfonate salt $\mathbf{2}$ which is currently commercially available. This compound was directly transformed into sulfonyl chloride $\mathbf{3}(\mathrm{SES}-\mathrm{Cl})$ by the action of phosphorus pentachloride, ${ }^{1}$ thionyl chloride, ${ }^{6}$ or sulfuryl chloride. ${ }^{7} \mathrm{SES}-\mathrm{Cl}$ is a distillable liquid (bp = $60{ }^{\circ} \mathrm{C} / 0.1 \mathrm{mmHg}$ ) which can be stored at room temperature.

\subsection{Protection of Amines}

The formation of sulfonamide $\mathbf{4}$ is usually carried out at low temperatures by reaction of the amine with an excess of SES-Cl $\mathbf{3}$ in the presence of triethylamine (eq 2, Table 1). In the case of aromatic or heterocyclic amines, sodium hydride is instead used as a base.

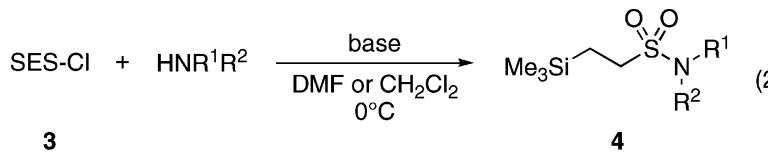

The simple and general synthesis of $N$-SES amino acids ${ }^{25,26}$ should be noted: it starts from the corresponding salt using a temporary trimethylsilane protection on the carboxylic acid function, followed by reaction with SES$\mathrm{Cl}$ (Scheme 3).

\section{Scheme $3^{a}$}

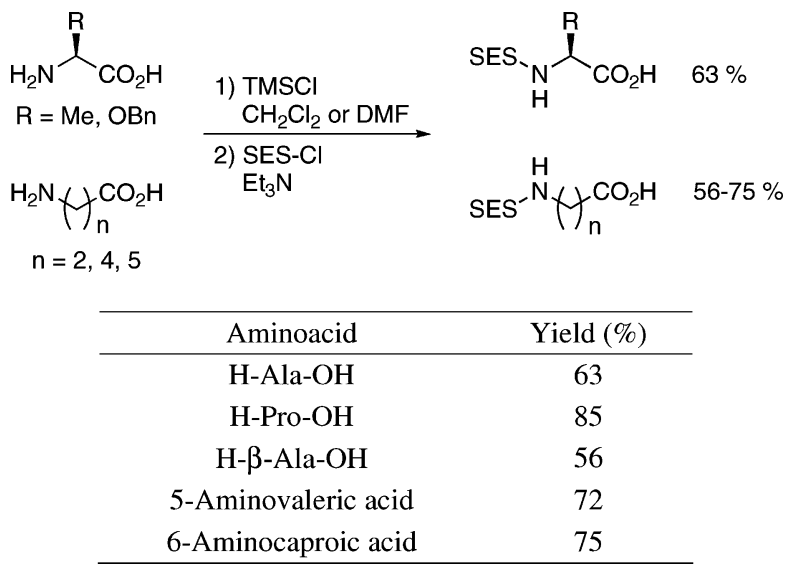

${ }^{a}$ Reprinted with permission from ref 25. Copyright 1999 Springer-Verlag $\mathrm{GmbH}$. 


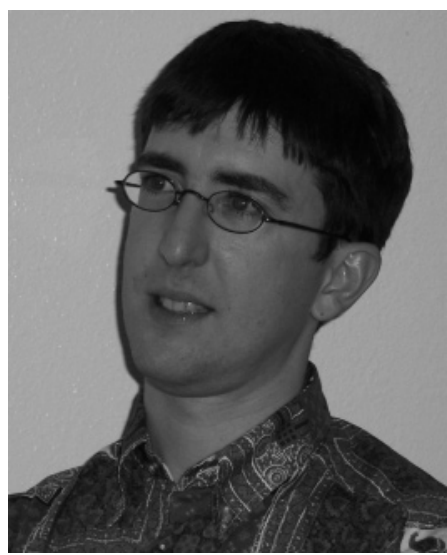

Patrice Ribière was born in Nîmes, France, in 1975. He obtained, in 1999 his engineer degree in chemistry from the Ecole Nationale Supérieure de Chimie de Montpellier, France. After nearly 1 year of national service as a scientist in the cellular biology department of the French Nuclear National Agency at Saclay, he joined, as a Ph.D. student, the team of Dr. F. Lamaty in the Laboratory of Aminoacids, Peptides and Proteins directed by Professor J. Martinez to work on PEG-supported chemistry. At the end of 2003 he obtained his doctorate degree and began postdoctoral research in the laboratory of Professor J. L. Montchamp at Texas Christian University (Fort Worth, TX), where he is currently working on $\mathrm{H}$-phosphinate chemistry.

These SES-protected amino acids were shown to react in peptide synthesis ${ }^{11,16,25,27-29}$ like the usual Boc, Z, or Fmoc amino acids (eq 3). No racemization was found in the formed peptide under the reported coupling conditions.

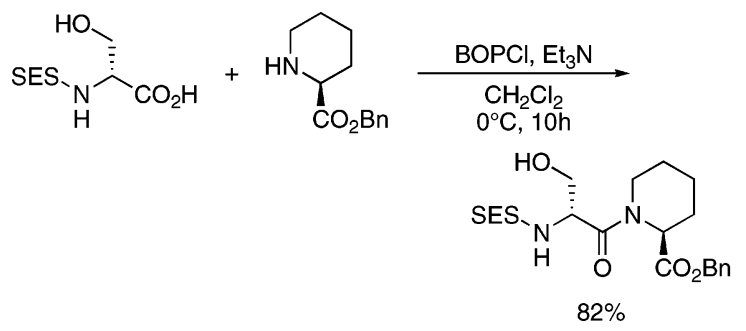

The amino function of the side chain of ornithine has been protected likewise or directly in aqueous medium ${ }^{30,31}$ without protecting the carboxylic acid function (eq 4). This protected ornithine has been used by Boger and co-workers in the synthesis of Ramoplanin, ${ }^{30-33}$ a lipoglycodepsipeptide with potent antibacterial activity (Scheme 4), and in the synthesis of the Chlorofusin cyclic peptide ${ }^{34}$ (Scheme 5).

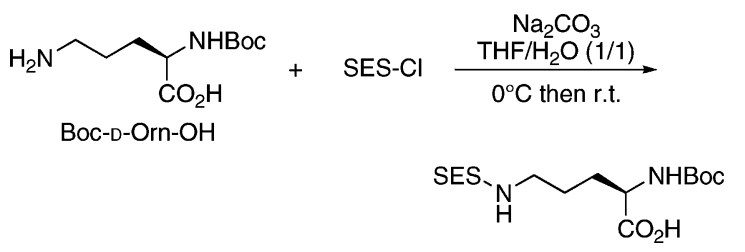

Under the general conditions of amine protection described by Weinreb, an alcohol is transformed into its corresponding sulfonate. This side reaction can be useful to further transform the alcohol function ${ }^{35}$ or prepare aziridines ${ }^{36}$ (Scheme 6).

\section{Direct Introduction of 2-(Trimethylsilyl)- ethanesulfonamide in Synthesis}

Over the years, a broad range of reagents and reactions were developed to directly introduce the SES-protected amine

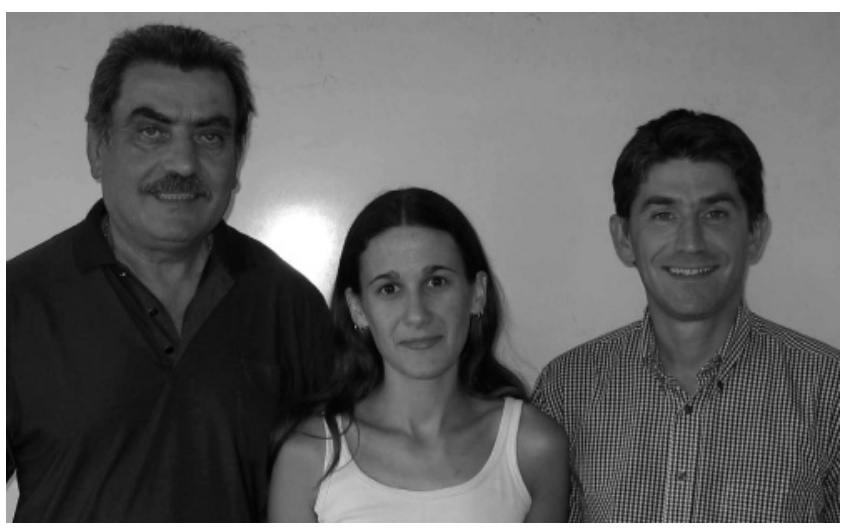

Valérie Declerck (middle) was born in Nemours, France, in 1980. During her undergraduate education at the Institute of Technology in Le Mans, she trained with Professor J. Lebreton at the University of Nantes in 2000. She then moved to the University of Montpellier, where she obtained her Diplôme d'Etudes Approfondies in 2003. Since 2003 she has been pursuing her Ph.D. under the direction of Dr. F. Lamaty. She is working on the aza-Baylis-Hillman reaction: synthesis of $\beta$-aminoesters and their applications (organometallic chemistry, heterocyclic chemistry, etc.).

Jean Martinez (left) studied chemistry at the Ecole Nationale Supérieure de Chimie de Montpellier (France). After receiving his Ph.D. degree in 1972, he was awarded a permanent position at the CNRS. He completed his Thèse d'Etat in 1976 under the direction of Professor F. Winternitz and performed postdoctoral studies with Professor E. Bricas in Orsay (France) and at Case Western University (Ohio) with Professor M. Bodansky. On his return to France, he pursued his research activities in the field of peptides and became successively head of various research laboratories in Montpellier, including the Chemistry and Pharmacology of Biologically Interesting Molecules Laboratory. In 1998 he was appointed Professor of the Faculty of Sciences and in 2001 Professor of the Faculty of Pharmacy. He is currently head of the Laboratory of Aminoacids, Peptides and Proteins and of the Max Mousseron Institute for Biomolecules. His research interests are peptide chemistry and pharmacology, stereoselective synthesis of amino acids, chemistry on polymeric supports, mass spectrometry, artificial protein synthesis, computer-assisted peptide search, and green chemistry.

Frédéric Lamaty (right) was born in Saint-Dizier, France, in 1966. He graduated as a chemical engineer in 1988 from the Ecole Supérieure de Chimie Industrielle de Lyon (France). In 1992 he received his Ph.D. degree from Purdue University under the supervision of Professor E. Negishi in the field of Pd-catalyzed cyclizations. He then joined, as a Rhône-Poulenc postdoctoral fellow, the group of Professor M. Julia at the Ecole Normale Supérieure in Paris to work on the synthesis of vitamin A. In 1994 he obtained a permanent position at the Centre National de la Recherche Scientifique (CNRS) in Montpellier and is currently working in the Laboratory of Aminoacids, Peptides and Proteins. His research interests include organic chemistry, catalysis, synthesis of amino acids, heterocyclic chemistry, polymer-supported chemistry, especially on PEG support, and green chemistry.

into a substrate. These synthetic possibilities allow the rapid production of a broad range of structures (Scheme 1). This structural diversity will be illustrated below with an emphasis on various types of reactions.

\subsection{Conversion of an Alcohol into a SES-Protected Amine}

This transformation, described for the first time in 1992 by Hart and co-workers, ${ }^{37}$ is performed by a Mitsunobu reaction between the alcohol function of the substrate and the diprotected amine SES-NHR, where R is a carbamatetype protecting group (Boc ${ }^{37-50}$ or $\mathrm{Z}^{40,41}$ ) or another SES protecting group. ${ }^{51}$ This second protecting group increases the acidity of the proton on the sulfonamide, which allows the Mitsunobu reaction to take place under very mild 
Table 1. Amine Protection ${ }^{a}$

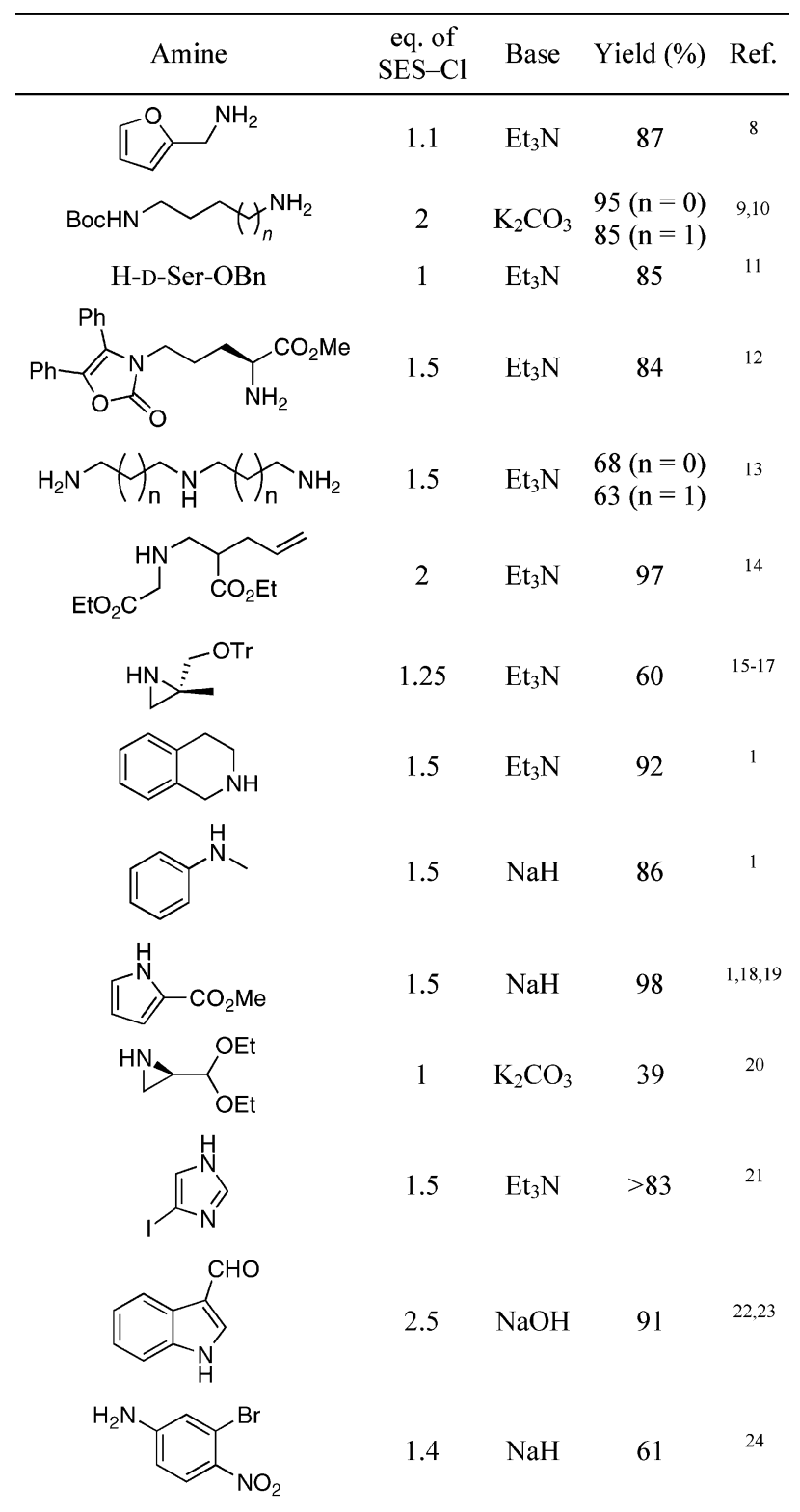

${ }^{a}$ Data taken from refs $1,8-18$, and $20-24$.

conditions (triphenylphosphine and diethylazodicarboxylate at room temperature), resulting in a quantitative yield.

In the case of a chiral alcohol, the Mitsunobu reaction generally occurs with inversion of configuration, as shown in the synthesis of $\alpha$-aminonitriles ${ }^{46}$ (Scheme 7). Acidic hydrolysis deprotects both the Boc and SES groups to yield the corresponding amino acids. Retention of the configuration was observed for specific substrates ${ }^{37,38}$ as a result of an adjacent disubstituted amide participation (eq 5).

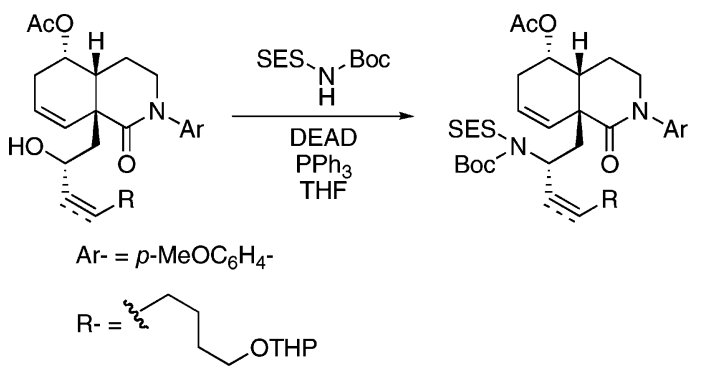

Scheme $4^{a}$

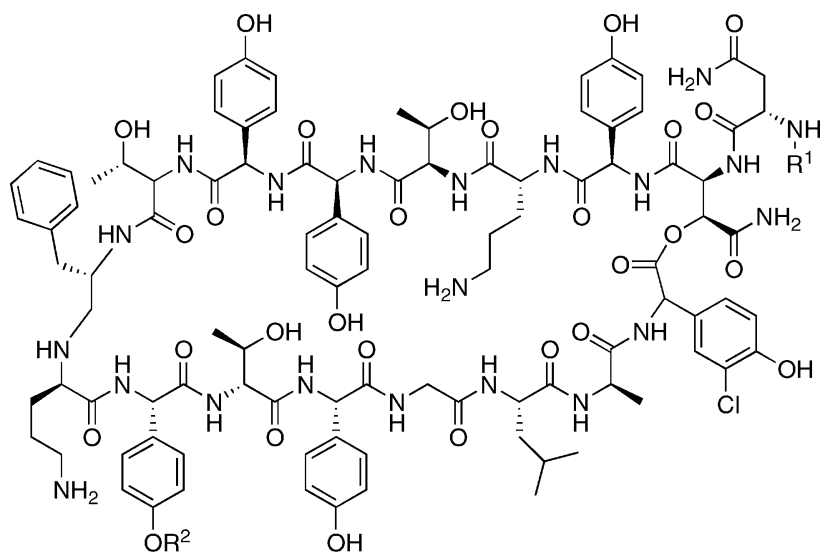

$\mathrm{R}^{1}=$
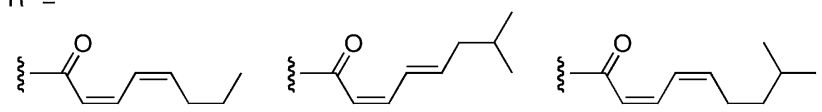

Ramoplanin A1

Ramoplanin A2 Ramoplanose

Ramoplanin A3

$\mathrm{R}^{2}=$

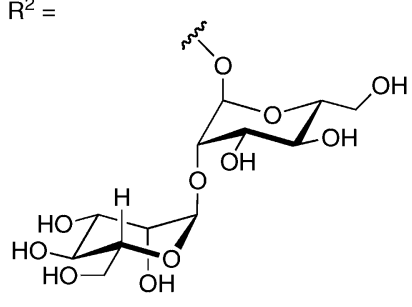

Ramoplanin A1-A3

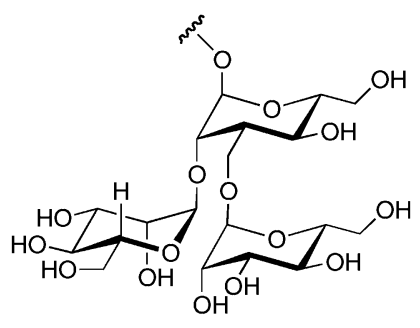

Ramoplanose
${ }^{a}$ Reprinted with permission from ref 30. Copyright 2002 American Chemical Society.

Scheme $5^{a}$

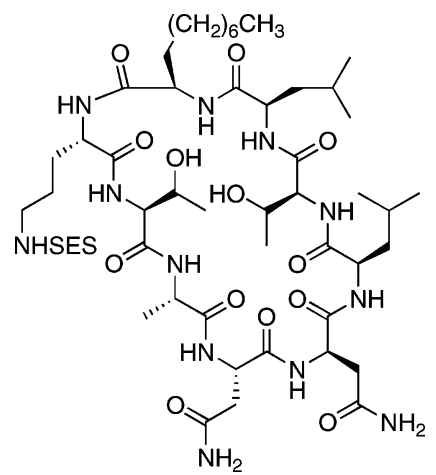

${ }^{a}$ Reprinted with permission from ref 34. Copyright 2003 American Chemical Society.

Selective deprotection of the Boc or $\mathrm{Z}$ protecting group in the presence of the SES protecting group is carried out as usual in acidic medium for the Boc group or via palladium hydroxide catalyzed hydrogenolysis for the $\mathrm{Z}$ group, yielding a SES amine which can be used further in synthesis (section 4). Elimination of the second SES group will be studied in the general section devoted to removal of this group (section 6.1).

\subsection{Reactions on 2-(Trimethylsilyl)ethanesulfonylimines}

\subsubsection{Formation of 2-(Trimethylsilyl)ethanesulfonylimines}

Several methods are described to form sulfonylimines (see Chemla and co-workers ${ }^{52}$ and references quoted therein). 


\section{Scheme $6^{a}$}

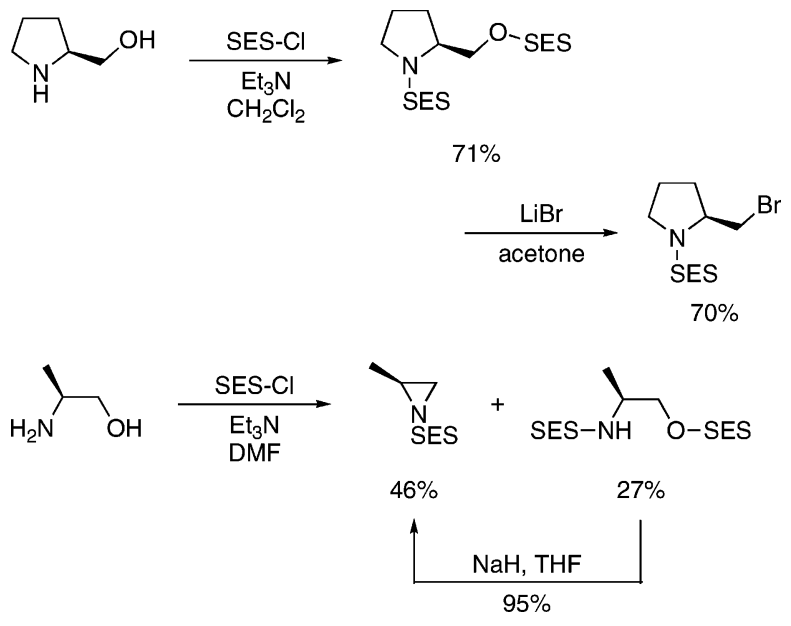

${ }^{a}$ Reprinted with permission from refs 35 and 36. Copyright 1997 Elsevier and 2005 American Chemical Society.

Scheme $7^{a}$
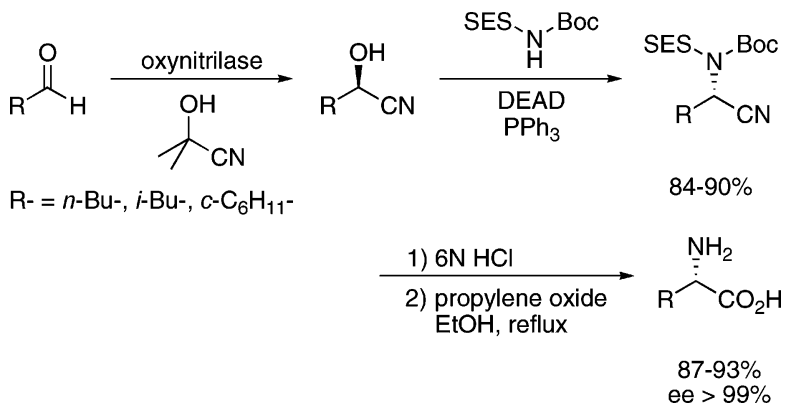
Verlag

${ }^{a}$ Reprinted with permission from ref 46. Copyright 1997 Georg Thieme

Some of them were adapted to synthesize SES sulfonylimines.

3.2.1.1. By Direct Condensation. The 2-(trimethylsilyl)ethanesulfonylimines $\mathbf{6}$ can be obtained by direct condensation between an aldehyde and SES $-\mathrm{NH}_{2} \mathbf{5}$ in the presence of a Lewis acid using a Dean-Stark azeotropic distillation apparatus to trap the released water (eq 6). This method, described by Proctor and co-workers for tosylimines, ${ }^{53}$ was employed by Aggarwal ${ }^{54,55}$ and $\mathrm{Lu}^{56}$ to afford aromatic 2-(trimethylsilyl)ethanesulfonylimines.

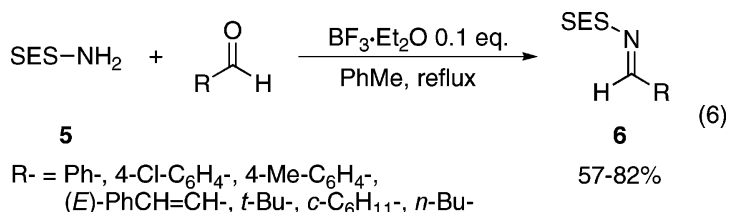

3.2.1.2. By the SES-NSO Intermediate. Sulfinylimines can be produced at room temperature from $\mathrm{N}$-sulfinyl-2(trimethylsilyl)ethanesulfonamide (SES-NSO 7) and aromatic or aliphatic aldehydes. Formation of the SES-NSO can be carried out by applying the method of Kresze ${ }^{57}$ to $\mathrm{SES}-\mathrm{NH}_{2} \quad \mathbf{5} .58,59$ The sulfonamide reacts with thionyl chloride to form the expected product and releases two equivalents of $\mathrm{HCl}$ (eq 7). The product is used directly after concentration of the solvent.

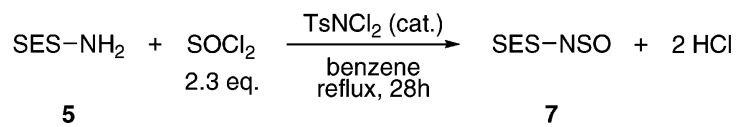

Another method, milder but requiring a longer work up step, involves the use of $N$-(chlorosulfinyl)imidazole, formed from imidazole and thionyl chloride in two steps. Purification is performed at each step by simple precipitation. The process was optimized by the group of $\mathrm{Kim}^{60}$ for tosylamine and various amines (Scheme 8) and used to form the SES-NSO 7 by Weinreb and co-workers. ${ }^{61,62}$

After formation of SES-NSO 7, the sulfonylimine 6 is quickly and easily obtained, ${ }^{58,59,61-63}$ sulfur dioxide being the only reaction byproduct (eq 8).

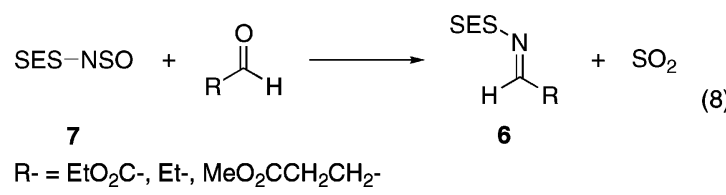

3.2.1.3. By Sulfinyl Chloride and the Hudson Reaction. Weinreb and co-workers ${ }^{64}$ also employed the Hudson reaction to provide easily available 2-(trimethylsilyl)ethanesulfonylimines. This reaction does not require any use of $\mathrm{SES}-\mathrm{NH}_{2} \mathbf{5}$ as precursor but 2-(trimethylsilyl)ethanesulfinyl

\section{Scheme 8}

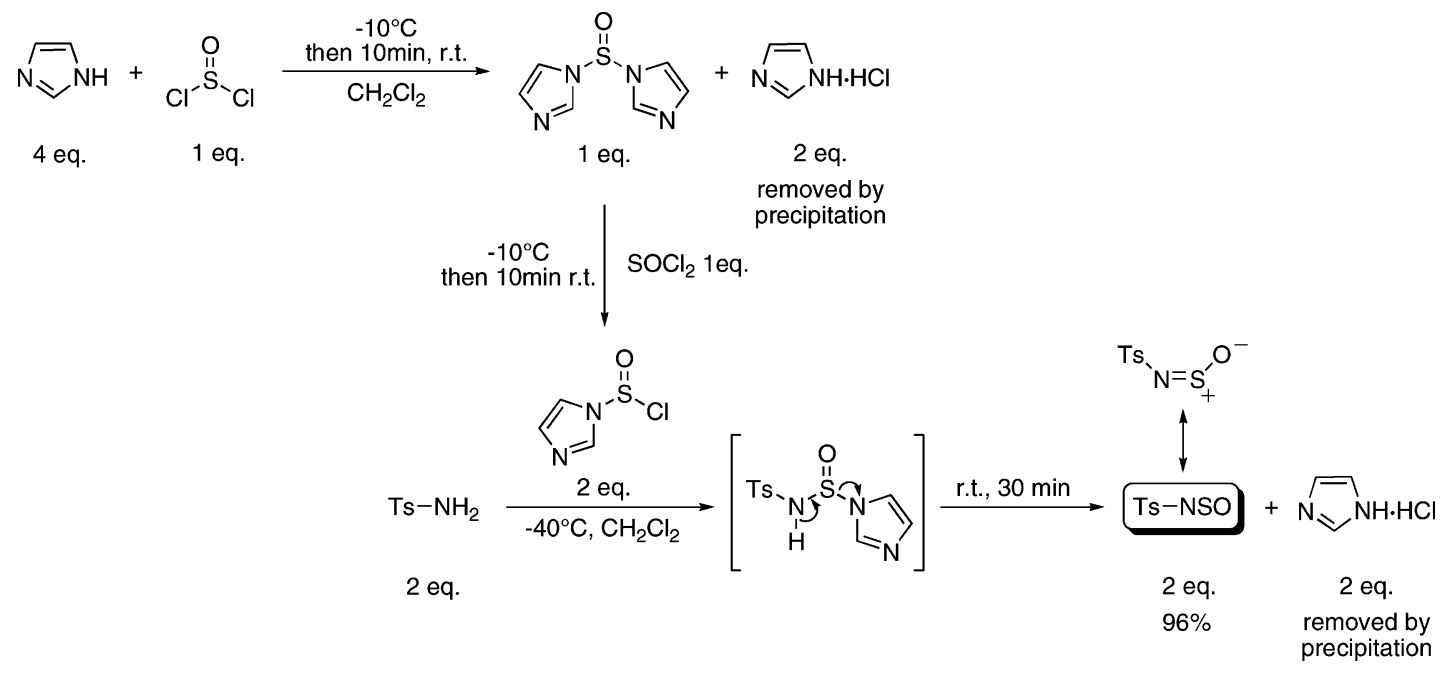

${ }^{a}$ Reprinted with permission from ref 60. Copyright 1985 Elsevier. 
Scheme $9^{a}$

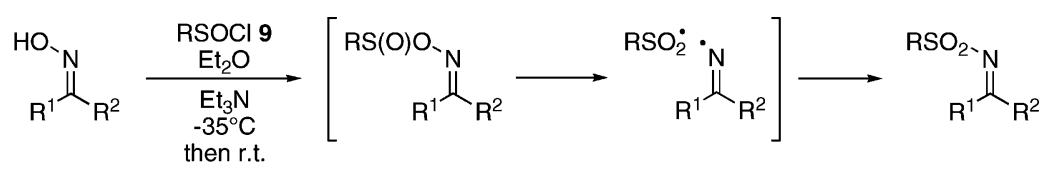

$\mathrm{R}-=\mathrm{TMS}-\mathrm{CH}_{2}-\mathrm{CH}_{2}-$

\begin{tabular}{cccccc}
\hline Oxime & Yield (\%) & Oxime & Yield (\%) & Oxime & Yield (\%) \\
\hline & 75 & & & &
\end{tabular}

${ }^{a}$ Reprinted with permission from ref 64. Copyright 2001 Georg Thieme Verlag.

\section{Scheme 10 ${ }^{a}$}

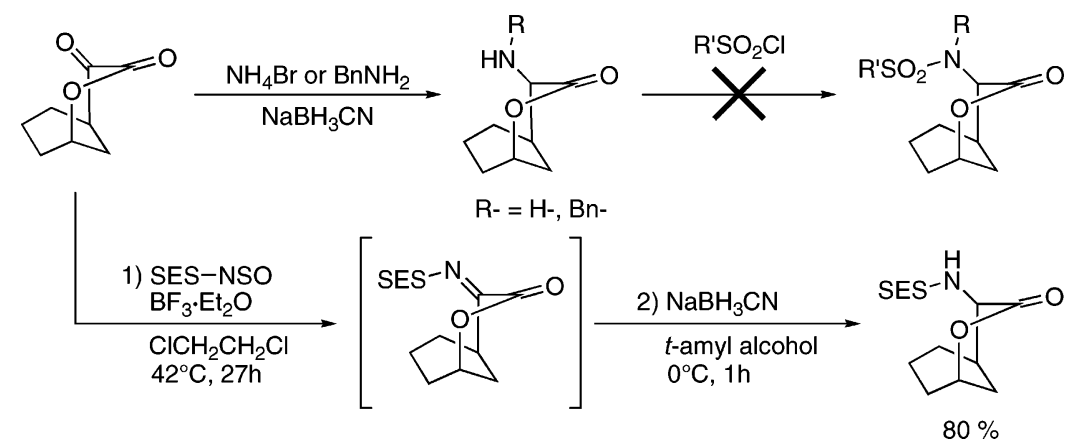

${ }^{a}$ Reprinted with permission from refs 58 and 63. Copyright 1988 and 1990 American Chemical Society.

chloride 9 , obtained by fragmentation of the sulfoxide $\mathbf{8}^{65,66}$ (eq 9).

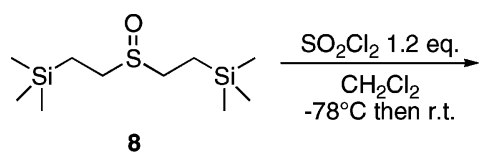<smiles>C[Si](C)(C)CCS(=O)Cl</smiles>

Treatment of an oxime ${ }^{64}$ with the sulfinyl chloride 9 affords a sulfinic ester intermediate. This product undergoes, at room temperature, a homolytic cleavage followed by a recombination which leads to the expected sulfonylimine (Scheme 9). The reaction provides 2-(trimethylsilyl)ethanesulfonylimines of diverse structures in good yields, even with oximes formed from ketones.

\subsubsection{Reduction}

Weinreb and co-workers developed in 1988 the reductive sulfonamidation ${ }^{58,63}$ for the synthesis of two antibiotics, Actinobolin and Bactobolin. Due to steric hindrance, the amine, resulting from the reductive amination of the corresponding $\alpha$-keto lactone, was unable to undergo the expected sulfonylation (Scheme 10). The reductive sulfonamidation directly provides the protected amine as a sulfonamide by reducing the nonisolated sulfonylimine formed from the $\alpha$-keto lactone and SES-NSO 7.
Scheme 11 ${ }^{a}$

$$
\begin{aligned}
& \text { SES-NSO } \left.\frac{\substack { \text { 1) } \mathrm{RCHO} \\
\begin{subarray}{c}{\mathrm{CH}_{2} \mathrm{Cl}_{2} \\
\text { r.t., } 1-2 \mathrm{~h}{ \text { 1) } \mathrm { RCHO } \\
\begin{subarray} { c } { \mathrm { CH } _ { 2 } \mathrm { Cl } _ { 2 } \\
\text { r.t., } 1 - 2 \mathrm { h } } }}{\mathrm{R}^{\prime}}\right] \\
& \mathrm{R}-=\mathrm{Et}-, i-\mathrm{Pr}-
\end{aligned}
$$

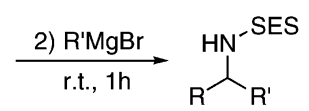

$$
\begin{aligned}
& \mathrm{R}^{\prime}-\mathrm{M} \text { = Me, vinyl- } \\
& \text { 65-67\% }
\end{aligned}
$$

${ }^{a}$ Reprinted with permission from ref 62. Copyright 1990 American Chemical Society.

This method was not used further; however, it is a possible strategy to obtain protected primary amines from the corresponding aldehydes or ketones.

\subsubsection{Nucleophilic Addition}

The highly electrophilic character of the SES imine allows good reactivity toward many organometallic compounds. In 1990 Weinreb and co-workers ${ }^{62}$ used this property for the first time. The SES imine, formed in situ, reacts with an excess of Grignard reagent to provide protected primary amines in moderate yields (Scheme 11).

Since the reactivity of this type of electrophile is high, less reactive organometallics were tested to allow a larger variety of functionalities and control of the chirality. Tomioka and co-workers ${ }^{67}$ added organozincs on several SES imines in the presence of a catalytic amount of copper(II) triflate and a chiral amidophosphine to obtain chiral sulfonamides in very good yields and enantiomeric excesses (Scheme 12). 
Scheme 12 ${ }^{a}$
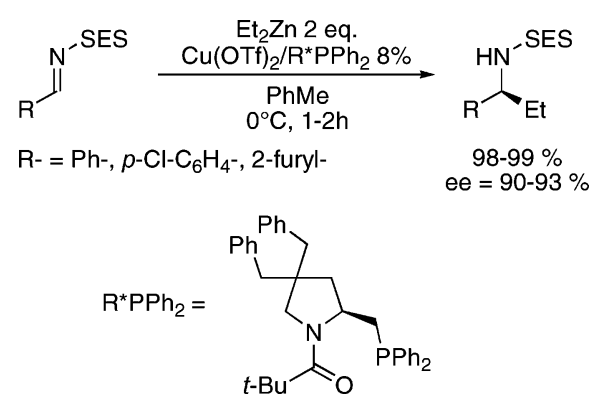

${ }^{a}$ Reprinted with permission from ref 67. Copyright 2000 American Chemical Society.

\section{Scheme $1^{a}$}
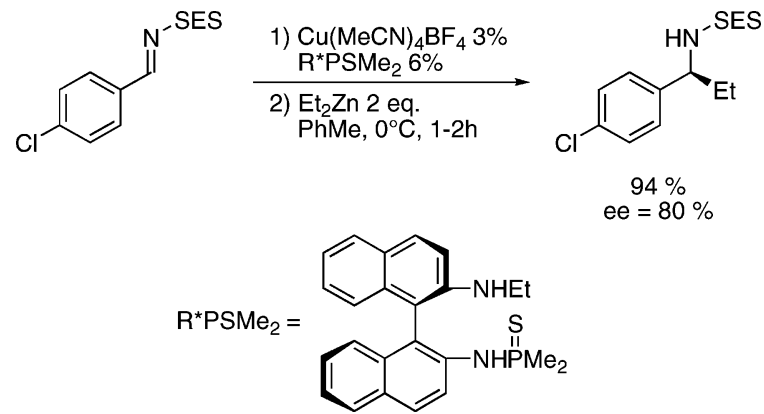

${ }^{a}$ Reprinted with permission from ref 68. Copyright 2003 American Chemical Society.

Scheme $14^{a}$

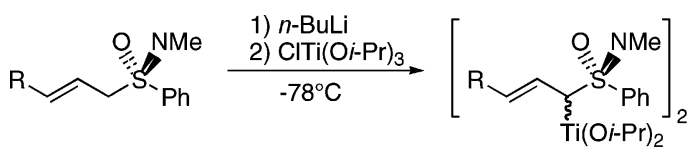

$\mathrm{R}^{-}=\mathrm{c}^{-} \mathrm{C}_{6} \mathrm{H}_{11^{-}}$
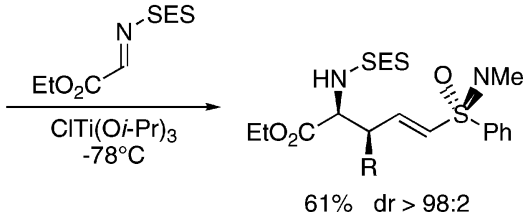

${ }^{a}$ Reprinted with permission from ref 59. Copyright 2002 American Chemical Society.

The putative mechanism relies on in situ formation of a zinc cuprate-phosphine complex and coordination of zinc or copper with a sulfonyl oxygen, followed by a 1,4-addition-type alkylation. Recently, the same reaction has been performed with a chiral binaphthylthiophosphoramide $-\mathrm{Cu}(\mathrm{I})$ catalyst by Shi and co-workers ${ }^{68}$ with similar results (Scheme 13).

A recent example of addition of organometallic reagents to SES imines was described in 2002 by Gais and coworkers. ${ }^{59}$ They used a chiral, sulfonimidoyl bis(allyl)titanium complex to form an $\gamma, \delta$-unsaturated $\alpha$-aminoester with high regio- and stereoselectivity (Scheme 14). In this case, the stereogenic center was part of the organometallic reagent.

However, regarding the synthesis of functionalized and chiral products, the greatest progress was achieved in 1999 when Lectka ${ }^{69,70}$ developed the first catalytic and enantioselective alkylation of $N, O$-acetals, protected mainly by the SES group, leading to $\gamma$-oxo- $\alpha$-amino acids (Scheme 15 ). This reaction is particularly interesting as a method to obtain various chiral $\alpha$-aminoesters from only one precursor, the SES hydroxyglycine 10, which is easier to form and more stable toward hydrolysis than the corresponding imine. The imine intermediate is formed in situ through the transsilylation of the first equivalent of enol silyl ether on the $\mathrm{N}, \mathrm{O}$-acetal, in the presence of a Lewis acid. Eventually, a second equivalent of silyl enol ether is necessary to perform the alkylation of the $\mathrm{Cu}(\mathrm{I})$ SES imine complex.

Finally, we can reference the addition of the masked activated formate $\mathrm{ROCH}(\mathrm{CN})_{2}$ to a SES imine under high pressure in the absence of a base ${ }^{71}$ (eq 10).

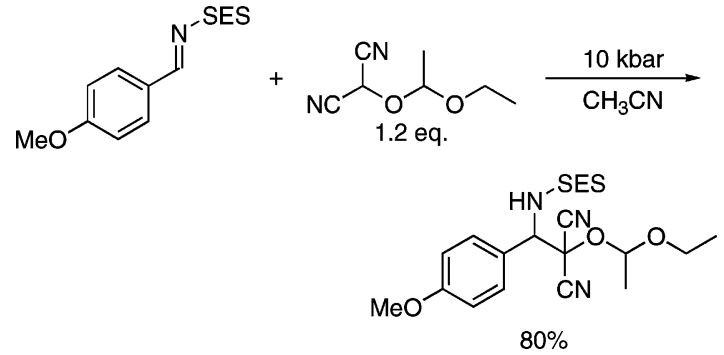

\subsubsection{Cycloadditions}

This type of reaction leads to heterocyclic compounds. The first cycloaddition ${ }^{61}$ on a SES imine was described by Weinreb and co-workers in 1989. $N$-sulfonylimine was trapped by a diene in a $[4+2]$ cycloaddition to lead to the imino Diels-Alder product (Scheme 16).

Another reaction, developed by Franck and co-workers, ${ }^{72-74}$ in which the SES imine is part of the heterodiene, also uses a $[4+2]$ cycloaddition (Scheme 17). A SES iminothione is formed in situ from the corresponding phthalimidothiosulfone

\section{Scheme $15^{a}$}

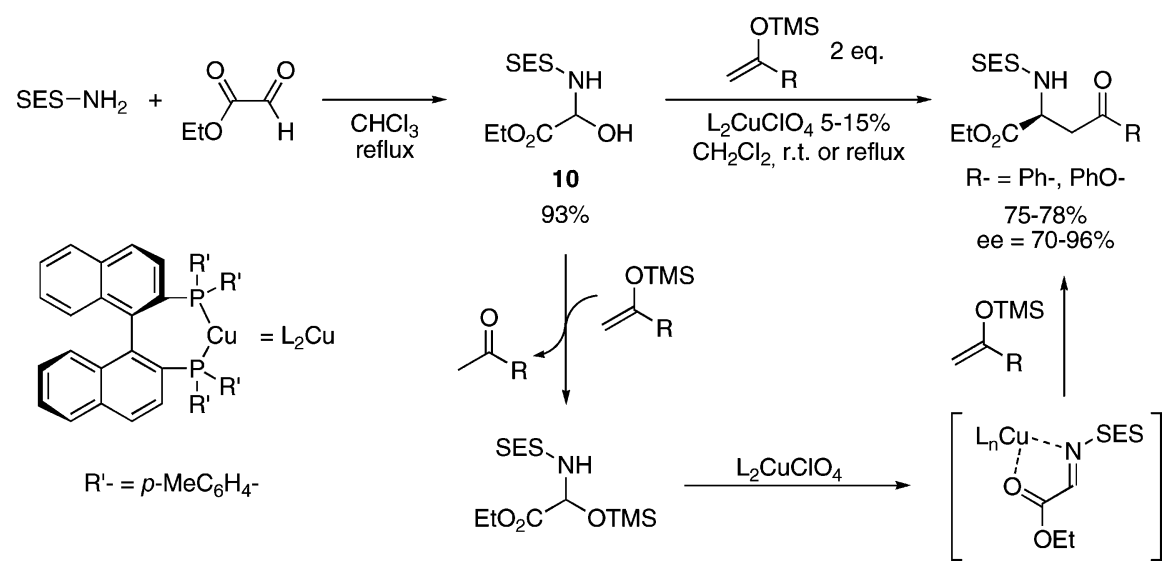

${ }^{a}$ Reprinted with permission from refs 69 and 70. Copyright 1999 Elsevier and 1999 American Chemical Society. 
Scheme $16^{a}$
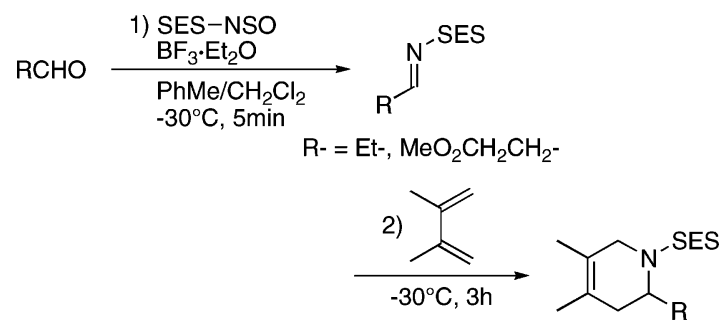

$56-58 \%$

${ }^{a}$ Reprinted with permission from ref 61. Copyright 1989 Elsevier.

Scheme $17^{a}$

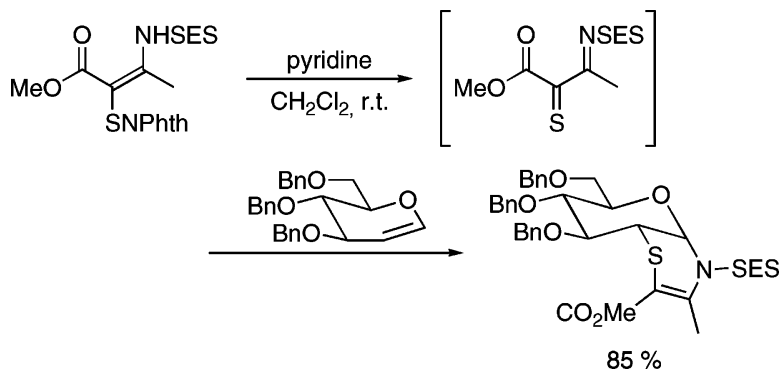

${ }^{a}$ Reprinted with permission from refs $72-74$. Copyright 2003 Elsevier and 1999, 2003 American Chemical Society.

\section{Scheme $18^{a}$}

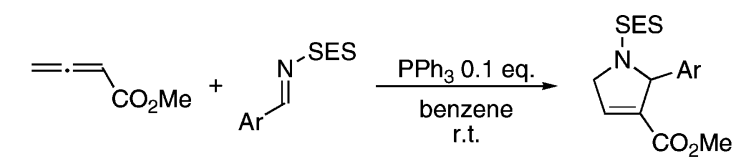

$\mathrm{Ar}-=\mathrm{Ph}-, p-\mathrm{Me}-\mathrm{C}_{6} \mathrm{H}_{4^{-}}, p-\mathrm{Cl}-\mathrm{C}_{6} \mathrm{H}_{4}^{-}$

$96-97 \%$
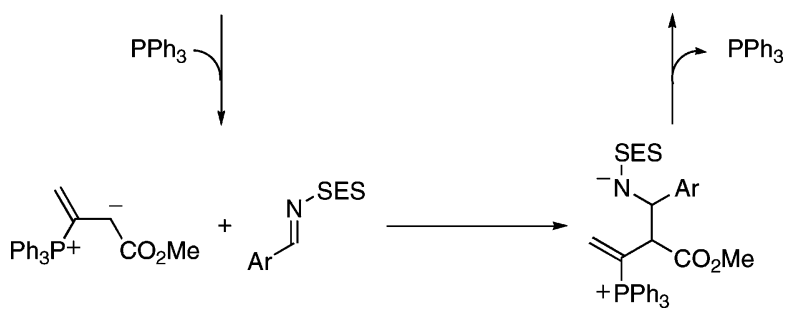

${ }^{a}$ Reprinted with permission from ref 56. Copyright 1998 American Chemical Society.

imine and reacts on the double bond of various glycals with a good yield and high regioselectivity. This original synthesis provides carbohydrates functionalized at the C-1 and C-2 carbons, which can then be used for the synthesis of glycopeptides.

$\mathrm{Lu}$ and co-workers ${ }^{56}$ developed the reaction of 2,3butadienoate with SES imines catalyzed by triphenylphosphine to provide 2,5-dihydropyrrole-3-carboxylates (Scheme 18) in excellent yields and high regioselectivities. Triphenylphosphine reacts with the allene to form an allyl carbanion, which is trapped by the SES imine in a $[3+2]$ cycloaddition. Zhu and co-workers ${ }^{75}$ recently adapted this method to the diastereoselective synthesis of 5-alkyl-2-aryl2,5-dihydropyrrole-3-carboxylates starting from $\gamma$-substituted allenoates (eq 11).

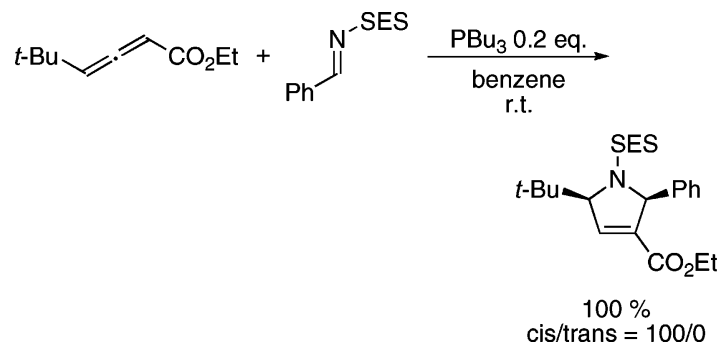

\subsubsection{Electrocyclization Reactions}

Recently, Parker and co-workers ${ }^{76}$ developed straightforward access to the synthesis of dihydroquinolines (Scheme 19). The vinyl quinone mono- or di-SES imide, accessible by oxidation of the corresponding aminophenol or phenylenediamine, undergoes a thermal $6 \pi$-electrocyclization in the presence of a polar aprotic additive. The vinyl quinone monoimide substrate can also provide the protected indole by photochemical cyclization.

\subsubsection{Aziridination Reaction}

Aziridines are an important class of organic compounds since they can undergo nucleophilic ring-opening reactions to provide products with a broad range of functionalities. Early in 1996 Aggarwal and co-workers ${ }^{54,55,77-81}$ investigated the catalytic asymmetric synthesis of aziridines protected by various groups, in particular the SES group.

Their strategy involves addition of a catalytic amount of a chiral sulfur ylide to a sulfonylimine. The sulfur ylide is generated by nucleophilic attack of a chiral sulfide on a carbenoid formed from a diazo compound and a metal salt (Scheme 20). Use of an electron-withdrawing group on the

\section{Scheme 19a}<smiles>[Y]c1ccc(NS(=O)(=O)c2ccccc2)c(C=CCC(C)=O)c1</smiles>

$X=N-S E S, O$<smiles></smiles>

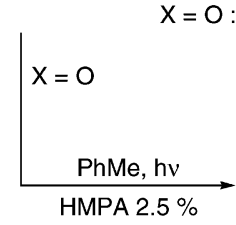

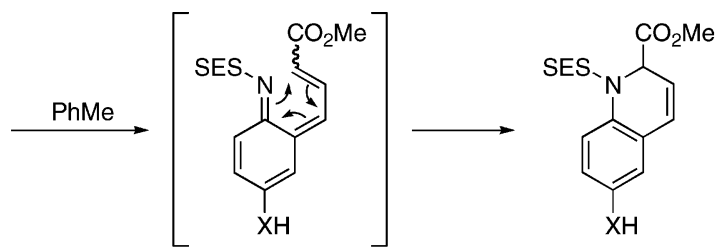

$X=N-S E S, 60 \%$ $\mathrm{X}=\mathrm{O}, 58 \%$ $X=N-S E S:$ HMPA $5 \%$, r.t.
$X=O:$ HMPA $2.5 \%$, reflux, dark<smiles>CC(=O)Cc1cc2cc(O)ccc2n1[S-]#[SH]</smiles> 
Scheme $20^{c}$

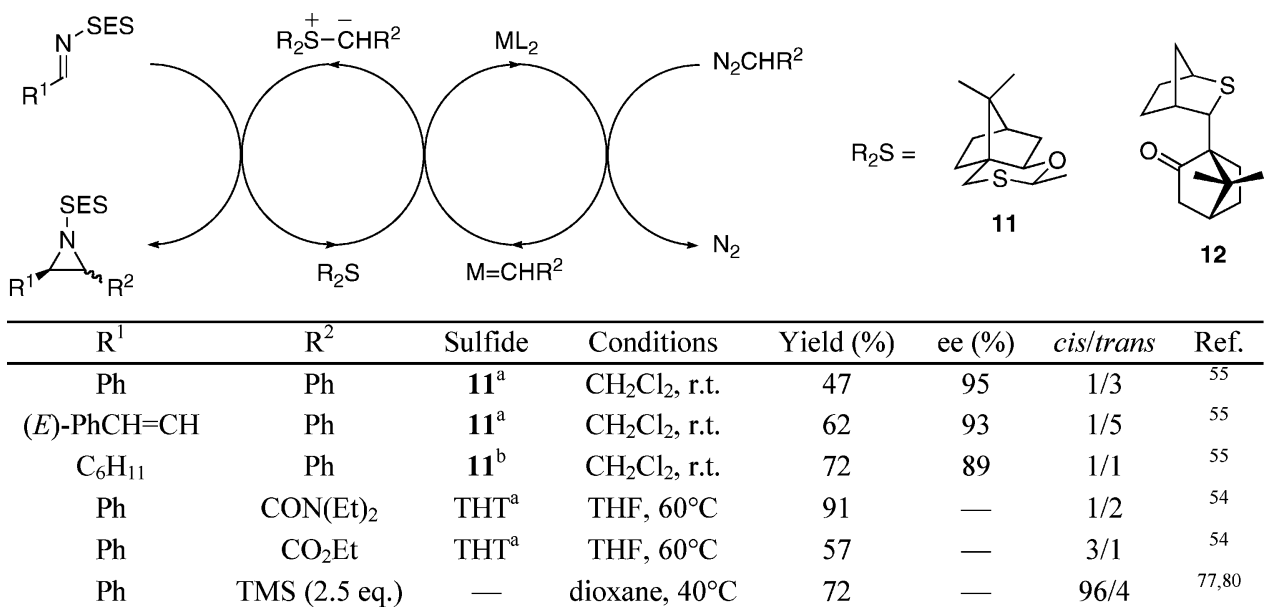

${ }^{a} 1 \% \mathrm{Rh}_{2}(\mathrm{OAc})_{4}, 0.2$ sulfide, 1.5 equiv of diazo compound. ${ }^{b} 1 \% \mathrm{Rh}_{2}(\mathrm{OAc})_{4}, 1$ equiv of sulfide, 1.5 equiv of diazo compound. ${ }^{c}$ Reprinted with permission from refs 54, 55, 77, and 80. Copyright 2001 Royal Society of Chemistry and 1996, 2000, 2002 American Chemical Society.

Scheme $21^{a}$

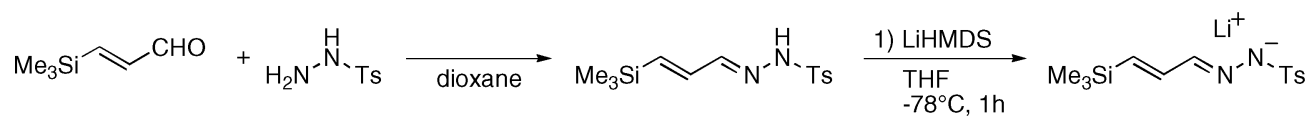

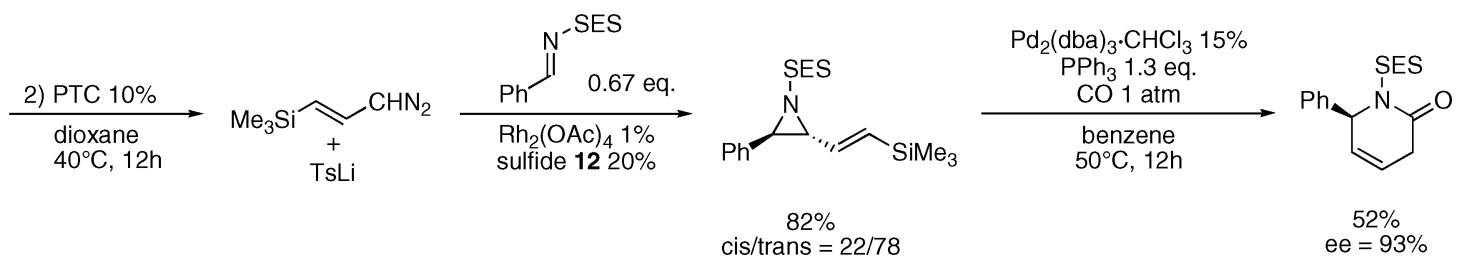

${ }^{a}$ Reprinted with permission from ref 79. Copyright 2001 Wiley VCH Verlag.

imine nitrogen, such as the SES group, disables the nonstereoselective direct reaction between the metallocarbene and the imine but also increases the rate of addition of the sulfur ylide to the imine. The metal salt used is usually $\mathrm{Rh}_{2}(\mathrm{OAc})_{4}$, but $\mathrm{Cu}(\mathrm{acac})_{2}$ can also be used with a slight decrease in both yield and enantiomeric excess.

Yields obtained by this method depend on the substituents, although the enantiomeric excess is always good. Functionalized diazoreagents $\mathrm{s}^{54}$ were tested in the racemic version with good results; however, diazoacetamide and diazoester require higher temperatures to react. Unlike the previous diazo compounds, diazoester gives predominantly the cis-aziridine as the major product. The same diastereoselectivity is obtained with commercial and stable trimethylsilyldiazomethane, ${ }^{77,80}$ which reacts directly without any need of a catalyst. Moreover, the formed $C$-silylaziridine can be coupled with an electrophile in the presence of a fluoride source without any cleavage of the SES group (eq 12).

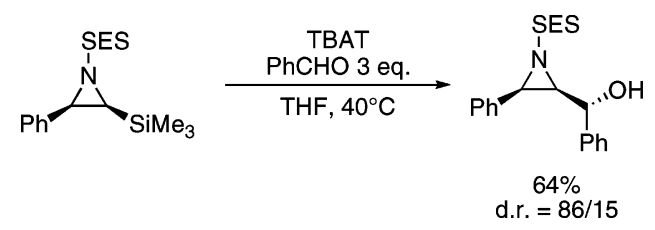

Aggarwal and co-workers were attempting to (i) diversify the source of carbene in order to find safer reaction conditions, compatible with various substrates and easy scale up, and (ii) develop chiral sulfides more stable than $\mathbf{1 1}$ (like
12 for example). This group developed a process using the Simmons - Smith carbenoid ${ }^{78}$ to generate sulfur ylides under neutral conditions, compatible with aliphatic enolizable imines. Another process was developed using the BamfordStevens reaction to generate the diazo compounds in situ from the corresponding aldehydes, transformed to the corresponding tosylhydrazones. ${ }^{79}$ This process can be extended to alkenyldiazomethanes, leading to the synthesis of unsaturated aziridines which are known to undergo ring expansion under a variety of conditions to yield $\beta$ - or $\delta$-lactams (Scheme 21). Recently, Aggarwal and co-workers used their asymmetric sulfur ylide-mediated aziridination process as a key step for the synthesis of the side chain of Taxol. ${ }^{81}$

\subsubsection{Aza-Baylis-Hillman Reaction}

Lamaty and co-workers described the use of SES- $-\mathrm{NH}_{2} \mathbf{5}$ in the three-component aza-Baylis-Hillman reaction to produce various unsaturated $\beta$-aminoesters. ${ }^{82}$ This reaction, which corresponds to coupling of the $\alpha$-position of methyl acrylate with an activated imine catalyzed by a tertiary amine like DABCO, implies in situ formation of the sulfonylimine before coupling with methyl acrylate (Scheme 22). A similar approach with a soluble polymer-supported sulfonamide, using SES as a linker, is described in section 7. Recently, Shi and co-workers described an asymmetric version of an aza-Baylis-Hillman reaction on preformed SES imines using a chiral tertiary amine derived from $(+)$-quinidine ${ }^{83}$ (Scheme 23) or a chiral phosphine ${ }^{84}$ (Scheme 24). 
Scheme $22^{a}$

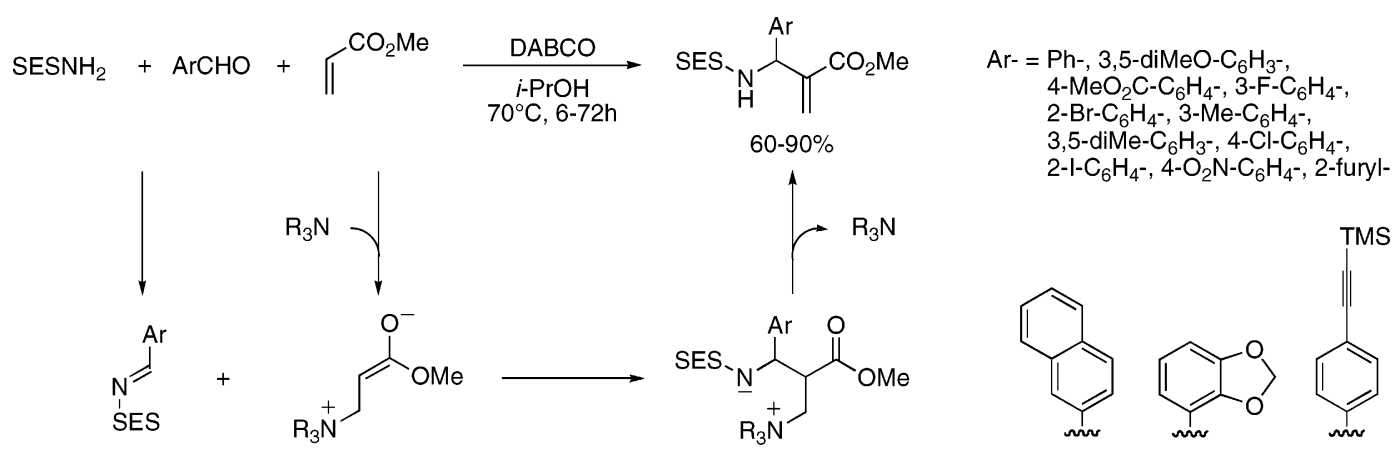

${ }^{a}$ Reprinted with permission from ref 82 . Copyright 2004 American Chemical Society.

\section{Scheme $23^{a}$}<smiles>CCN=Cc1ccc(C)cc1</smiles>
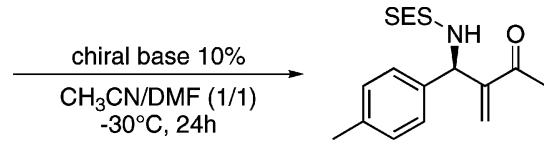

$71 \%$
ee $=80 \%$

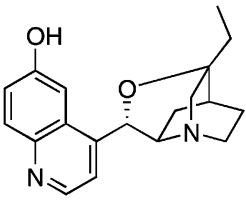

chiral base

${ }^{a}$ Reprinted with permission from ref 83 . Copyright 2005 Wiley VCH Verlag.

\section{Scheme $24^{a}$}
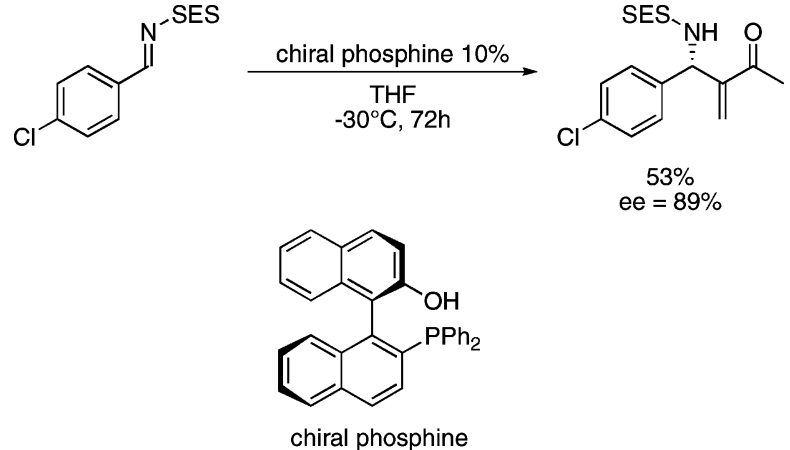

${ }^{a}$ Reprinted with permission from ref 84. Copyright 2005 American Chemical Society.

\section{3. (N-SES-imino) Phenyliodinane or SESN=IPh Reagent}

\subsubsection{Synthesis of SES Aziridines}

In 1999 Dodd and co-workers ${ }^{85}$ developed a new iminoiodinane reagent for the Evans copper-catalyzed aziridination method (Scheme 25). This first [ $N$-(alkylsulfonyl)-imino]phenyliodinane $\mathbf{1 3}$ is synthesized from $\mathrm{SES}-\mathrm{NH}_{2} \mathbf{5}$ and iodobenzene diacetate in a quantitative yield as a stable solid, although water sensitive, which can be stored under argon at $-20{ }^{\circ} \mathrm{C}$. This product is a nitrene precursor which reacts with olefins in the presence of a copper catalyst to provide the corresponding aziridines. The reaction was performed on various olefins (terminal, electron rich, electron poor, or cyclic) in moderate yields and in a stereospecific manner since only trans-aziridines were isolated from trans-olefins.

The SES aziridines are sufficiently activated to allow ring opening by nucleophiles ${ }^{86,87}$ such as sodium borohydride (eq
Scheme $25^{a}$
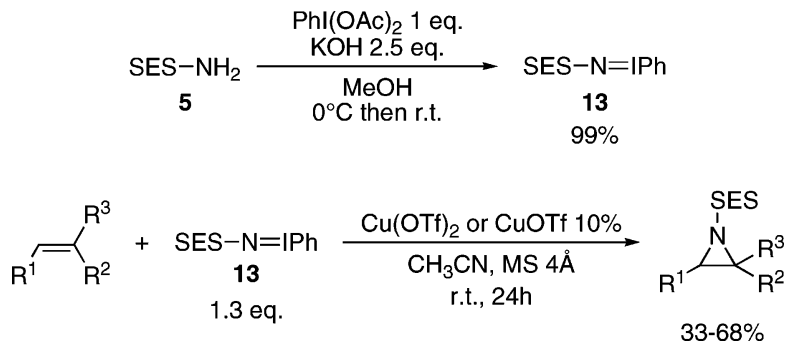

\begin{tabular}{|c|c|c|}
\hline Substrate & Catalyst & Yield \\
\hline & $\begin{array}{c}\mathrm{Cu}(\mathrm{OTf})_{2} \\
\text { CuOTf }\end{array}$ & $\begin{array}{l}58 \\
68\end{array}$ \\
\hline & $\mathrm{Cu}(\mathrm{OTf})_{2}$ & 40 \\
\hline $\mathrm{CO}_{2} \mathrm{Me}$ & $\begin{array}{c}\mathrm{Cu}(\mathrm{OTf})_{2} \\
\text { CuOTf }\end{array}$ & 39 \\
\hline $\mathrm{O}_{2} \mathrm{Me}$ & $\mathrm{Cu}(\mathrm{OTf})_{2}$ & 49 \\
\hline $\mathrm{Me}$ & $\begin{array}{c}\mathrm{Cu}(\mathrm{OTf})_{2} \\
\mathrm{CuOTf}\end{array}$ & $\begin{array}{l}52 \\
60\end{array}$ \\
\hline & $\mathrm{Cu}(\mathrm{OTf})_{2}$ & 47 \\
\hline $\mathrm{Ph}$ & $\mathrm{Cu}(\mathrm{OTf})_{2}$ & 48 \\
\hline & $\mathrm{Cu}(\mathrm{OTf})_{2}$ & 34 \\
\hline & $\mathrm{Cu}(\mathrm{OTf})_{2}$ & 55 \\
\hline & CuOTf & 67 \\
\hline & $\begin{array}{c}\mathrm{Cu}(\mathrm{OTf})_{2} \\
\mathrm{CuOTf}\end{array}$ & 43 \\
\hline
\end{tabular}

${ }^{a}$ Reprinted with permission from ref 85. Copyright 1999 American Chemical Society.

13). This method was also used for the aziridination of steroids, such as 11-pregnene-3,20-dione, to develop the synthesis of aziridinyl or amino steroids. The Dodd group used this method for the synthesis of Enduracididine, a marine amino acid..$^{88,89}$

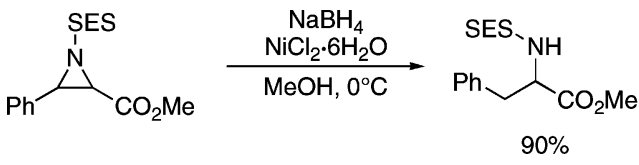

Lately, to avoid the difficulty of handling the iminoiodinane 13, Dodd and co-workers ${ }^{90}$ developed a "one-pot" version of this reaction (Scheme 26). Compound 13 was formed in situ from the easily accessible iodosylbenzene 
Scheme $26^{a}$

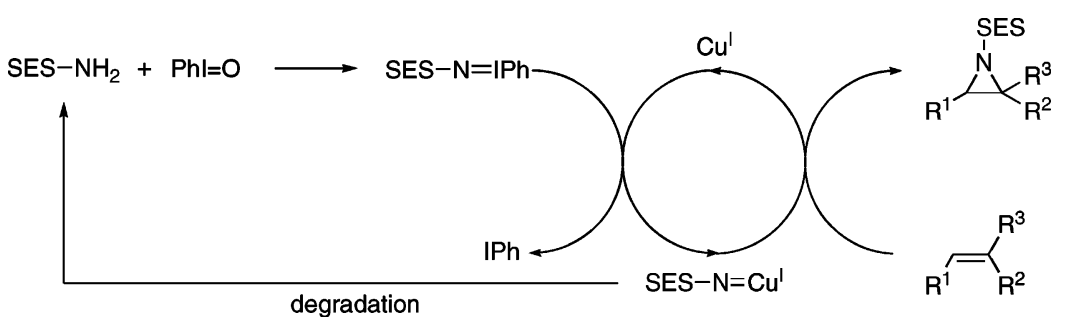

${ }^{a}$ Reprinted with permission from ref 90 . Copyright 2001 American Chemical Society.

Scheme $27^{a}$

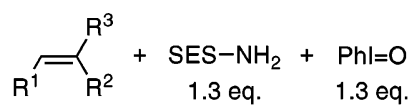

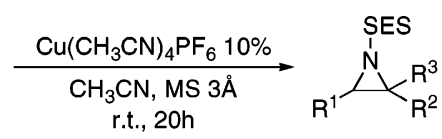

\begin{tabular}{cccc}
\hline Substrate & Yield (\%) & Substrate & Yield (\%) \\
\hline $\mathrm{CO}_{2} \mathrm{Me}$ & 43 & & \\
\hline $\mathrm{CO}_{2} \mathrm{Me}$ & 53 &
\end{tabular}

${ }^{a}$ Reprinted with permission from ref 90. Copyright 2001 American Chemical Society.

$(\mathrm{PhI}=\mathrm{O})$ and $\mathrm{SES}-\mathrm{NH}_{2} \mathbf{5}$ (Scheme 27). Yields are very close to those obtained with iminoiodinane $\mathbf{1 3}$ and, despite the presence of $\mathrm{PhI}=\mathrm{O}$, which is a powerful oxygen donor, the rate of epoxidation is very low (lower than $10 \%$ in the absence of $\mathrm{SES}-\mathrm{NH}_{2}$ ). This method greatly simplifies the copper-catalyzed aziridination of olefins.

The synthesis of chiral SES aziridines was also performed by Komatsu and co-workers ${ }^{91}$ using a chiral nitridomanganese complex activated by silver salt and SES-Cl 3 (Scheme 28). Like for the sulfonyliminoiodinane process, this reaction proceeds through a nitrogen-atom transfer. Although yields

\section{Scheme $28^{a}$}
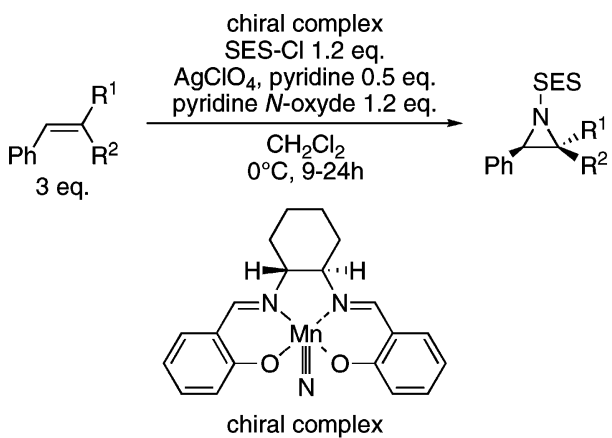

\begin{tabular}{cccc}
\hline $\mathrm{R}^{1}$ & $\mathrm{R}^{2}$ & Yields (\%) & ee (\%) \\
\hline $\mathrm{H}$ & $\mathrm{H}$ & 60 & 40 \\
$\mathrm{Me}$ & $\mathrm{H}$ & 70 & 83 \\
$n-\mathrm{Pr}$ & $\mathrm{H}$ & 50 & 85 \\
$i-\mathrm{Pr}$ & $\mathrm{H}$ & 62 & 90 \\
$c-\mathrm{C}_{6} \mathrm{H}_{11}$ & $\mathrm{H}$ & 62 & 93 \\
$\mathrm{H}$ & $\mathrm{Me}$ & 37 & 24
\end{tabular}

${ }^{a}$ Reprinted with permission from ref 91. Copyright 2002 American Chemical Society. are comparable with those of the preceding process, the diversity of substrate is lower and the reaction requires an excess of olefin.

\subsubsection{Synthesis of SES Sulfoximines}

These are synthesized ${ }^{92,93}$ under the conditions described for the preparation of aziridines from the corresponding sulfoxides in the presence of SESN=IPh 13 and a copper catalyst (eq 14).

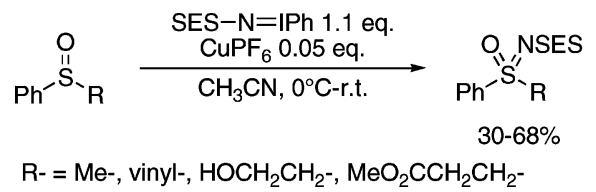

\subsection{Sulfonamidoglycosylation}

Two reagents derived from $\mathrm{SES}-\mathrm{NH}_{2} \mathbf{5}$ were used to introduce a protected nitrogen on a glycal double bond. They both provide 2 - $\alpha$-aminosugars in two steps. Their use depends on the stereochemistry of the glycal substrate.

\subsubsection{SES- $\mathrm{NH}_{2} /\left(\right.$ (sym-coll) ${ }_{2} \mathrm{ClO}_{4}$}

In 1992 Danishefsky's method of iodosulfonamidation was adapted $^{94,95}$ to introduce $\mathrm{SES}-\mathrm{NH}_{2}$ on a glycal (Scheme 29). The use of $\mathrm{I}(\mathrm{sym} \text {-coll })_{2} \mathrm{ClO}_{4}$ leads to a trans-diaxial-1,2iodosulfonamide. Its rearrangement in the presence of a base followed by nucleophilic substitution of this product provides a 2- $\alpha$-sulfamidyl-2-deoxy derivative with the nucleophile attached to $\mathrm{C}-1$ on the $\beta$-face.

This method was used for the total synthesis of aminosaccharides such as the sialyl-Lewis $X$ antigen, ${ }^{94,95}$ the selective Chitinase inhibitor Allosamidin, ${ }^{96}$ an antibiotic analogue of Moenomycine A,97,99 and a glycopeptide ${ }^{98}$ carrying full H-type 2 human blood group specificity.

Petillo and co-workers ${ }^{100}$ described the epimerization at the C-1 position of trans-1,2-iodosulfonamides, depending on the protecting groups of the starting glycal and the reaction and purification conditions. Because the reaction with a nucleophile proceeds via an aziridine intermediate (Scheme $30)$, the $\beta$-epimer is inert to any coupling conditions.

\subsubsection{SES-NBr 2}

In the case of a glycal with an $\alpha$-face hindered by an ether function at $\mathrm{C}-3$, the use of $\mathrm{SES}-\mathrm{NBr}_{2} 14$ allows the introduction in two steps of the protected amine at the C-2 position on the $\alpha$-face (Scheme 31). $\mathrm{SES}-\mathrm{NBr}_{2} \mathbf{1 4}$ is synthesized by bromination of SES- $\mathrm{NH}_{2} \mathbf{5}$ with a rather low yield. Like its iodo analogue, this reagent provides a 
Scheme 29a
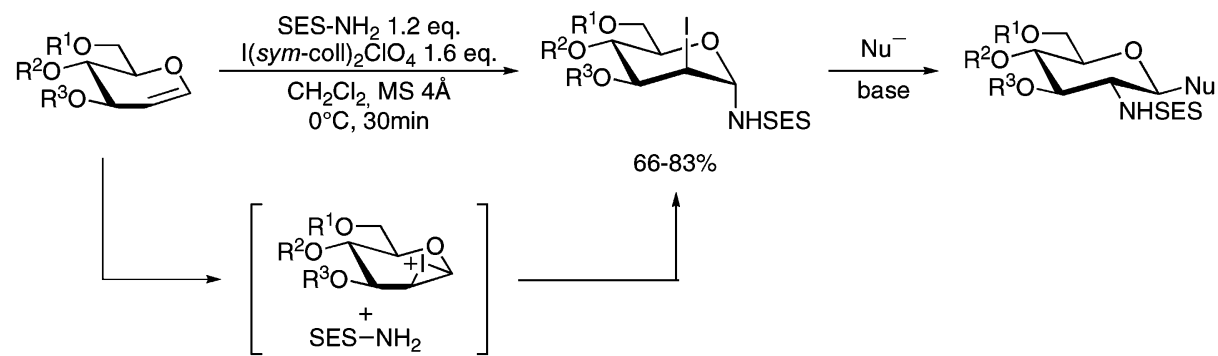

$66-83 \%$

\begin{tabular}{cccccccc}
\hline $\mathrm{R}^{1}$ & $\mathrm{R}^{2}$ & $\mathrm{R}^{3}$ & Yield (\%) & Nucleophile/Base & Conditions & Yield (\%) & Ref. \\
\hline TBDPS- & sugar & sugar & 82 & $\mathrm{Bu}_{3}$ SnOBn & AgOTf, THF, -78 ${ }^{\circ} \mathrm{C}$ & 64 & 95 \\
Bn- & Bn- & Bn- & 78 & azasugar/LTMP & AgOTf, THF, - $78^{\circ} \mathrm{C}$ & 49 & 96 \\
Bn- & sugar & Bn- & 66 & LiOH & THF $/ \mathrm{H}_{2} \mathrm{O}, 0^{\circ} \mathrm{C}-$ r.t. & 95 & 97 \\
Bn- & sugar & Bn- & 83 & EtSH/LiHMDS & DMF & 85 & 98
\end{tabular}

${ }^{a}$ Reprinted with permission from refs 95, 96, 97, and 98. Copyright 1997 Elsevier, 2001 Wiley VCH Verlag, and 1995, 1996 American Chemical Society.

\section{Scheme $30^{a}$}

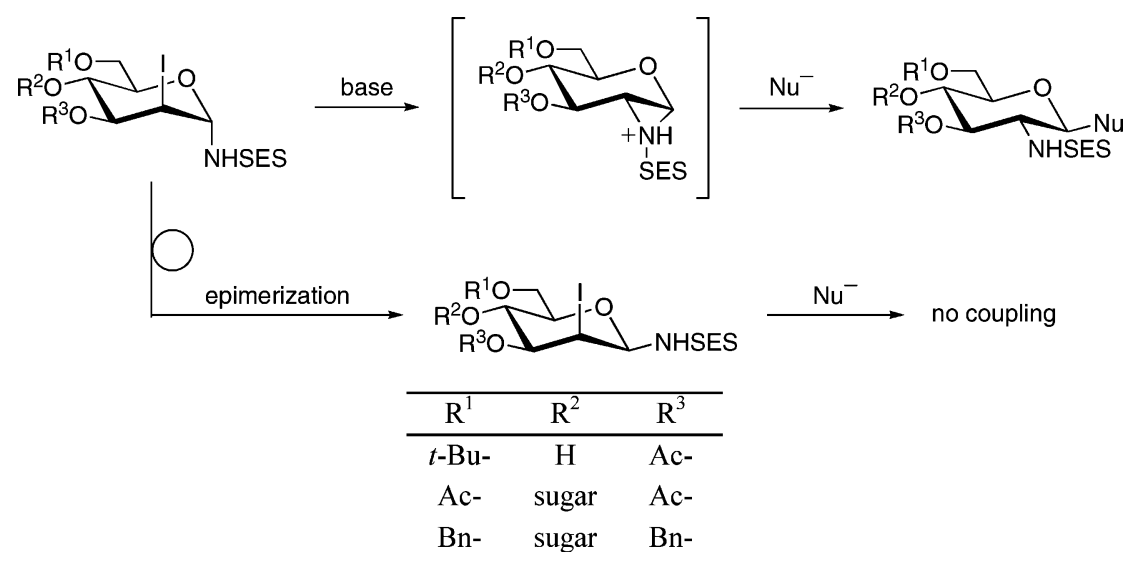

${ }^{a}$ Reprinted with permission from ref 100. Copyright 2001 American Chemical Society.

Scheme $31^{a}$

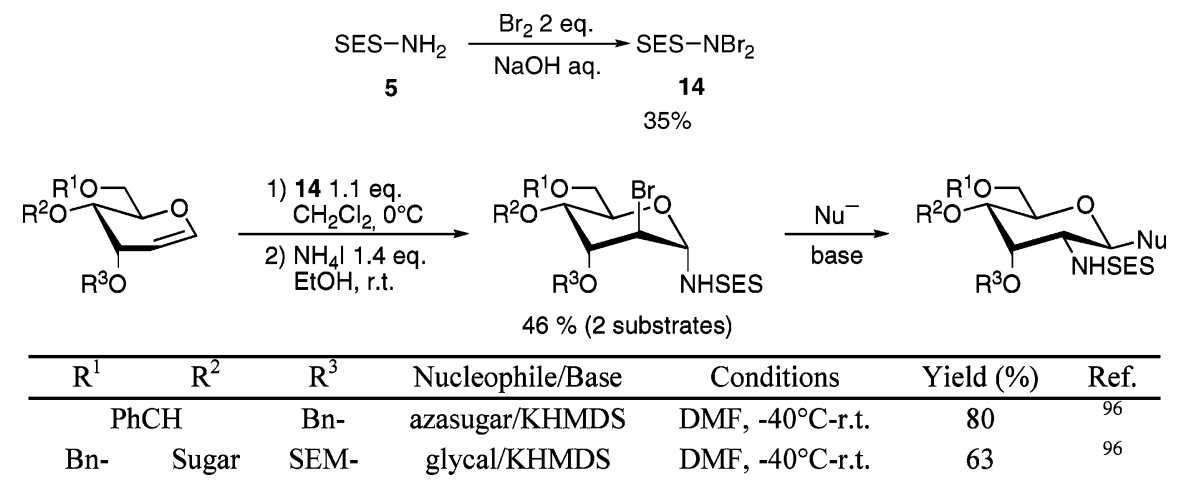

${ }^{a}$ Reprinted with permission from ref 96. Copyright 1996 American Chemical Society.

trans-diaxial 1,2-bromosulfonamide that undergoes rearrangement during glycosylation of the nucleophile.

\subsection{Di-SES-Sulfodiimide}

Dimerization of SES-NSO 7 affords the corresponding sulfodiimide 15. During the total synthesis of Agelastatin by Weinreb and co-workers, ${ }^{101,102}$ this reagent undergoes a Sharpless/Kresze ene reaction to afford the allylic amination product with very good regio- and stereoselectivity (Scheme 32). Recently, Hale and co-workers ${ }^{103,104}$ described the enantiospecific synthesis of (-)-Agelastatin A from a SES-protected known aziridine via ring-closing metathesis (RCM).

\section{6. $\mathrm{SESN}_{3}$}

For the first time Reggelin and co-workers ${ }^{105}$ recently described the use of SES-N ${ }_{3}$, generated in situ from SES-Cl 3 and $\mathrm{NaN}_{3}$. This reagent acts as a nitrene precursor in Bach's imination reaction to provide a SES-protected monosulfoximine (eq 15).

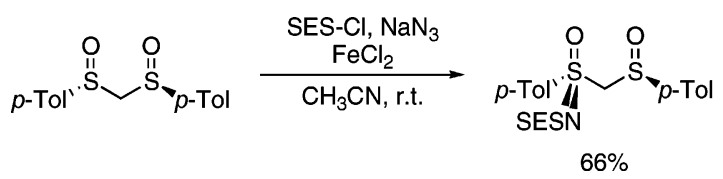


Scheme $32^{a}$

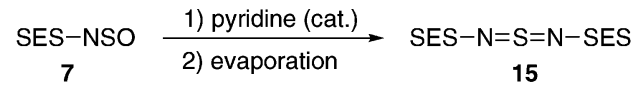
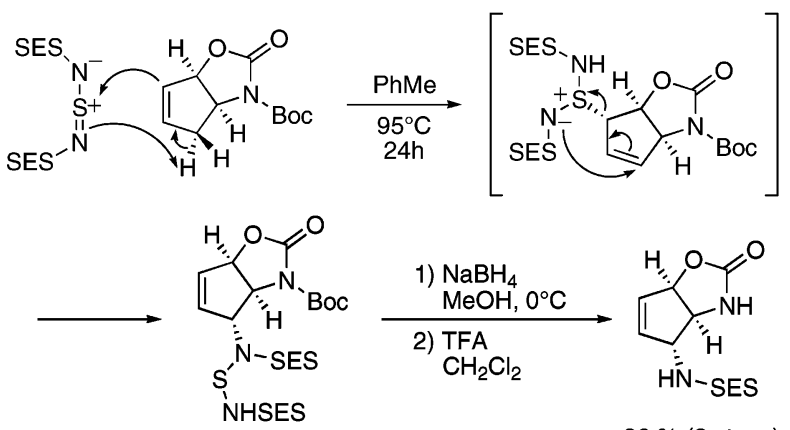

$86 \%$ (3 steps)

${ }^{a}$ Reprinted with permission from ref 101. Copyright 1999 American Chemical Society.

The Williams ${ }^{106}$ group described the synthesis of $N$-acyl sulfonamides using thio acid and azide. They adapted this method to $\mathrm{SES}-\mathrm{N}_{3}$ in order to promote the $N$-alkylation of an amide precursor for the synthesis of Epoxomicin. The reaction proceeds via a thiatriazoline intermediate formed by a $[2+3]$ cycloaddition or a stepwise diazo transfer-like mechanism. This intermediate then decomposes stepwise or by a retro- $[2+3]$ reaction to yield the amide (Scheme 33).

Recently, Chang and co-workers ${ }^{107}$ described a coppercatalyzed multicomponent reaction in which sulfonyl azides react with a wide range of alkynes and water to give amides. SES-N ${ }_{3}$ reacts efficiently with phenylacetylene in this process to give the desired amide in an excellent yield (eq 16).

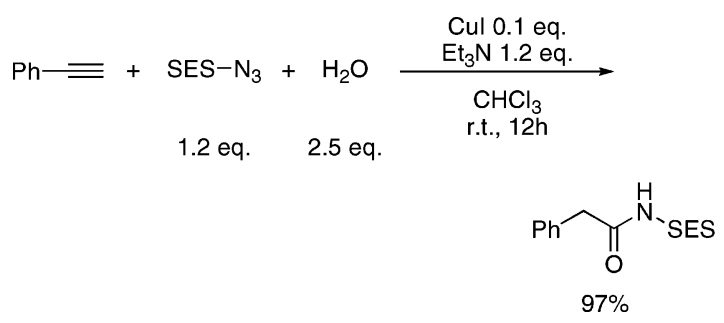

\section{SES as an Activating Group}

The acidity of the sulfonamide proton (Table 2) allows one to carry out alkylation reactions under mild conditions or Mitsunobu reactions. ${ }^{49,108}$ While the acidity has not been measured with SES $-\mathrm{NH}_{2}$, it can be considered to be similar to the acidity of $\mathrm{MeSO}_{2} \mathrm{NH}_{2} .{ }^{109}$
Table 2. Acidity of Several Ammonia Derivatives ${ }^{a}$

\begin{tabular}{lc}
\hline & $\mathrm{p} K_{\mathrm{a}}(\mathrm{DMSO})$ \\
\hline $\mathrm{NH}_{3}$ & 4.1 \\
$\mathrm{PhCO}_{2} \mathrm{NH}_{2}$ & 23.4 \\
$\mathrm{~F}_{3} \mathrm{CCO}_{2} \mathrm{NH}_{2}$ & 17.2 \\
$\mathrm{PhSO}_{2} \mathrm{NH}_{2}$ & 16.1 \\
$\mathrm{MeSO}_{2} \mathrm{NH}_{2}$ & 17.5
\end{tabular}

${ }^{a}$ Reprinted with permission from ref 109. Copyright 1988 American Chemical Society.

\subsection{N-Alkylations}

Except for the synthesis of an $(\alpha)$-porphyrine, ${ }^{110,111}$ linear triamines, ${ }^{112}$ and cyclic triamines using $\mathrm{SES}-\mathrm{NH}_{2},{ }^{113}$ the reactions involve primary amines protected by the SES group. The alkylation is efficient in its intermolecular ${ }^{10,13,46}$ and intramolecular versions. The intermolecular alkylation was used in the synthesis of natural polyamines ${ }^{10}$ (eq 17) or in the synthesis of cyclic amino acids by ring-closing metathesis $^{114}$ (a similar approach to these cyclic amino acids anchored on a polymer-supported SES group is described in section 7). This reaction has also been used in the synthesis of pyrrolines starting from unsaturated $\beta$-aminoesters ${ }^{82}$ (Scheme 34).

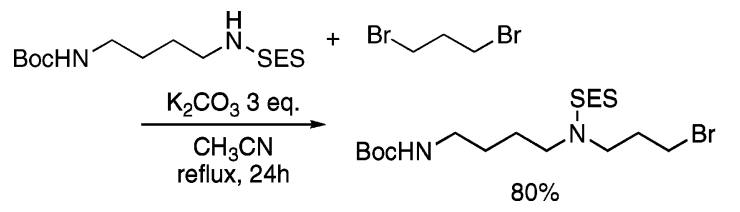

The intramolecular reaction was used in the total synthesis of the pentacyclic structure of Manzamine A, ${ }^{37,115,116}$ aziridines, ${ }^{117}$ (Scheme 35) and analogues of biological molecules. ${ }^{12}$ During the synthesis of the marine alkaloid Manzamine A, ${ }^{45,115}$ a 15-membered macrocycle was formed in a good yield using the usual alkylation conditions (eq 18).
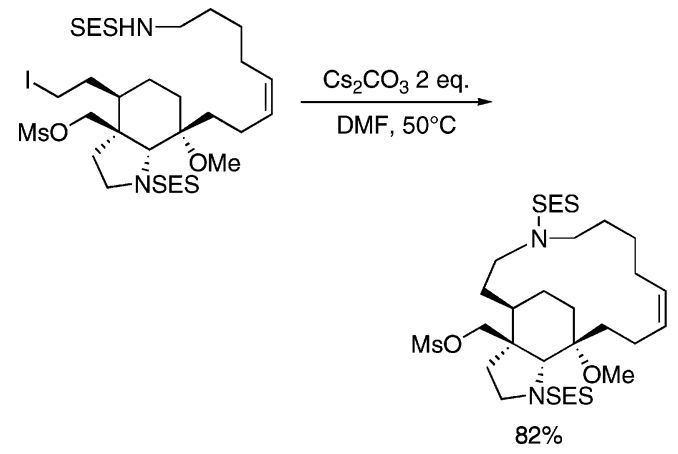

\section{Scheme $33^{a}$}

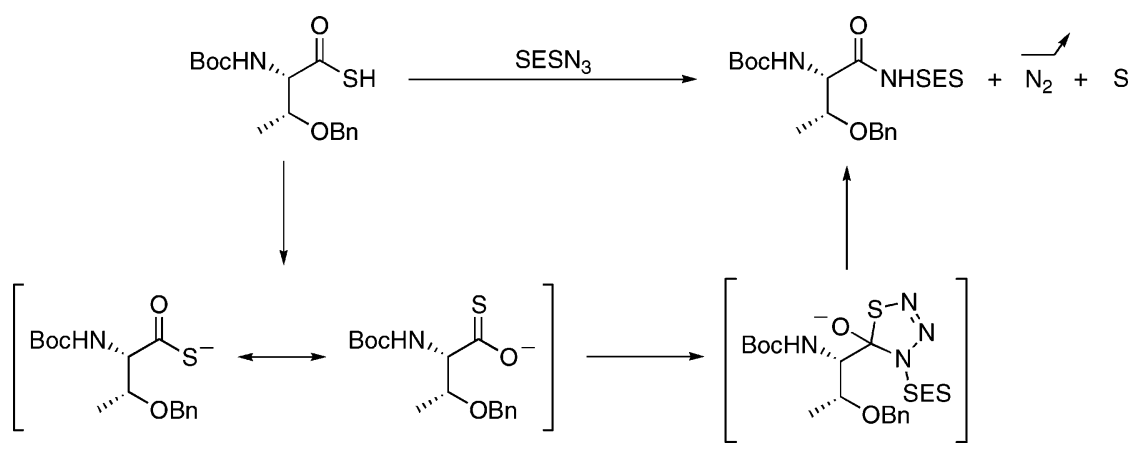

${ }^{a}$ Reprinted with permission from ref 106. Copyright 2004 American Chemical Society. 
Scheme 34

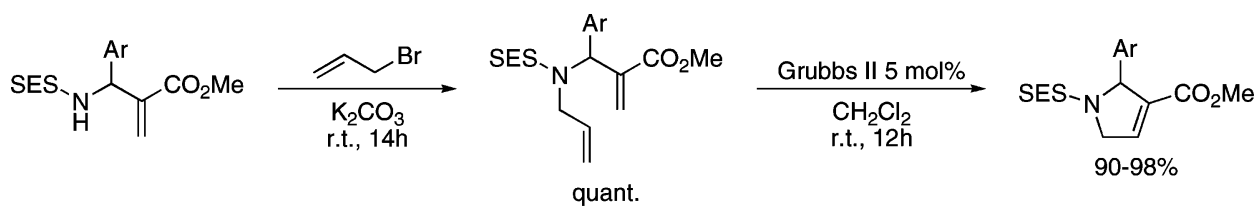
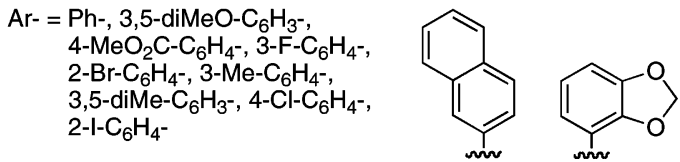

${ }^{a}$ Reprinted with permission from ref 82. Copyright 2004 American Chemical Society.

Scheme $35^{a}$

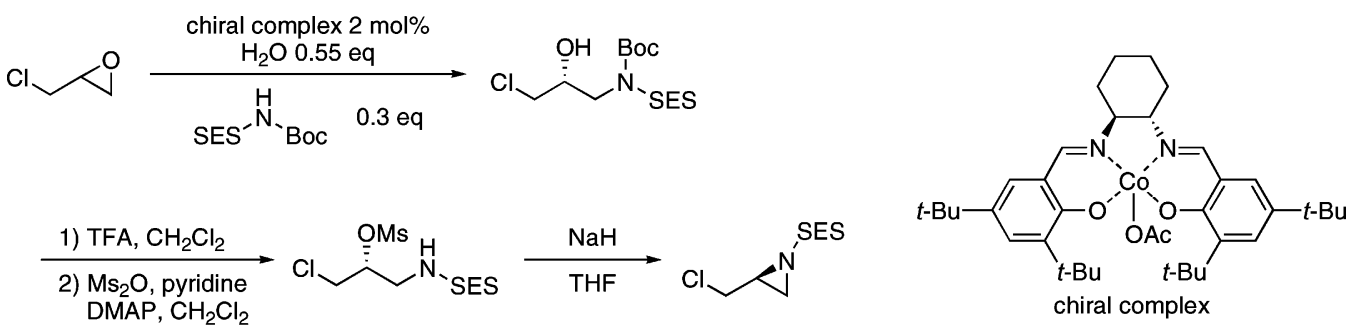

${ }^{a}$ Reprinted with permission from ref 117 . Copyright 2004 Wiley VCH Verlag.

Scheme $36^{a}$<smiles>COCC[C@H]1CCC[C@@H](O)[C@]1(CCNS(=S)NCOC)CCOC</smiles>
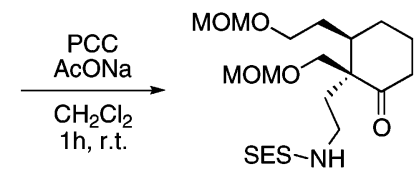

$\mathrm{MOMO} \sim$

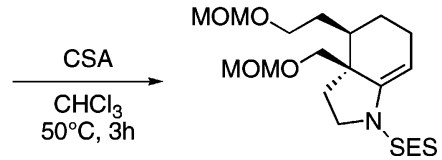

${ }^{a}$ Reprinted with permission from refs 43 and 45. Copyright 1998 Elsevier.

\subsection{Nucleophilic Additions}

During the synthesis of Manzamine A, Yamamura and coworkers $^{43,45}$ used a dehydration in acidic medium to form a cyclic ene-sulfonamide (Scheme 36 ).

In the synthesis of Manzamine A, ${ }^{44}$ during Boc deprotection in the presence of a Lewis acid, a spontaneous cyclization occurred due to the attack of the sulfonamide on the epoxide of the sulfonamide (eq 19).

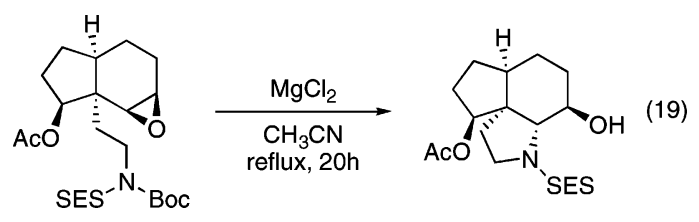

During the synthesis of an analogue of Ptilomycalin A, Hart and co-workers ${ }^{40,41}$ prepared a bicyclic guanidine by formation of a thioimidate which was then attacked by the SES sulfonamide in basic medium (Scheme 37).

Lee and co-workers ${ }^{50}$ carried out a Michael addition of a SES-protected primary amine on benzyl propiolate to form a $\beta$-aminoacrylate that was used for the synthesis of (-)Indolizidin 223AB (Scheme 38).
Scheme $37^{a}$
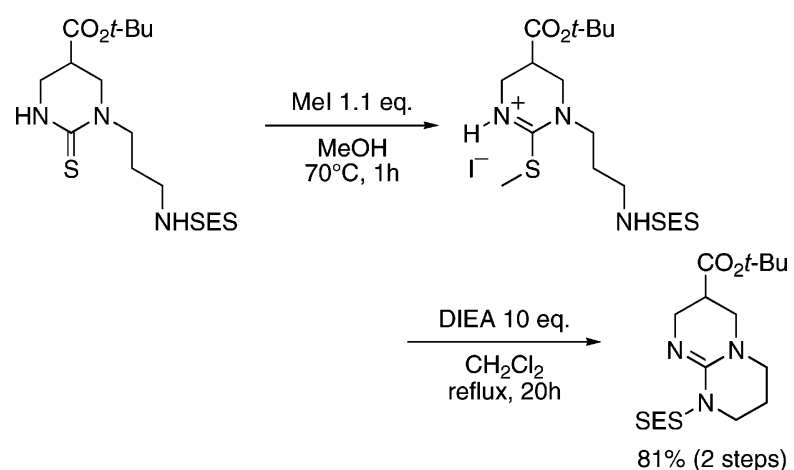

${ }^{a}$ Reprinted with permission from refs 40 and 41 . Copyright 1994 The Japan Institute of Heterocyclic Chemistry and 1995 Elsevier.

\section{Scheme $38^{a}$}
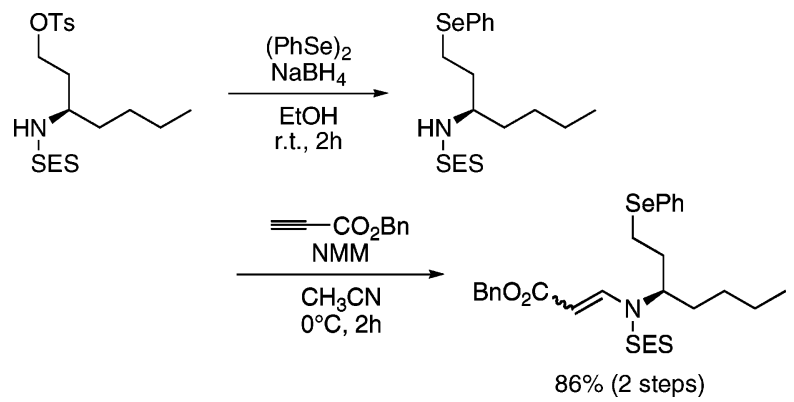

${ }^{a}$ Reprinted with permission from ref 50. Copyright 2000 American Chemical Society.

\subsection{Mitsunobu Reactions}

In the case of SES-protected primary amines, few examples of the Mitsunobu reaction have been described. An intramolecular reaction was described to provide a perhydro1,4-diazepin-2-one $\mathrm{e}^{25,26}$ (eq 20) which is a putative mimic of a peptide $\gamma$-turn with an ethylene link.

A similar cyclization has been performed in the presence of palladium and titanium catalysts ${ }^{36}$ (eq 21). 


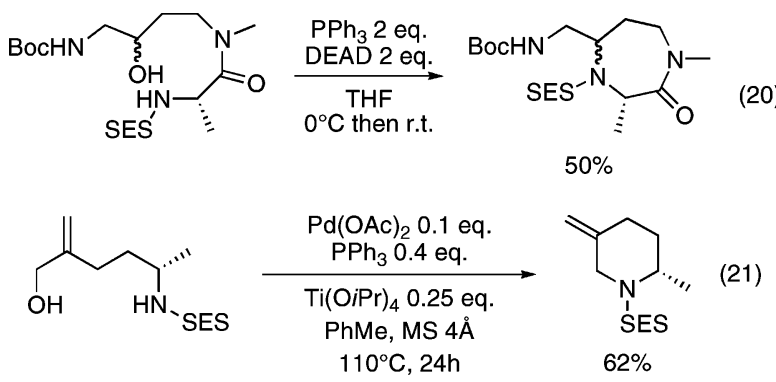

An intermolecular Mitsunobu reaction was used by Ohno and co-workers ${ }^{118}$ in the synthesis of 1,4-oxazepine (Scheme 39).

\section{Scheme 39a}

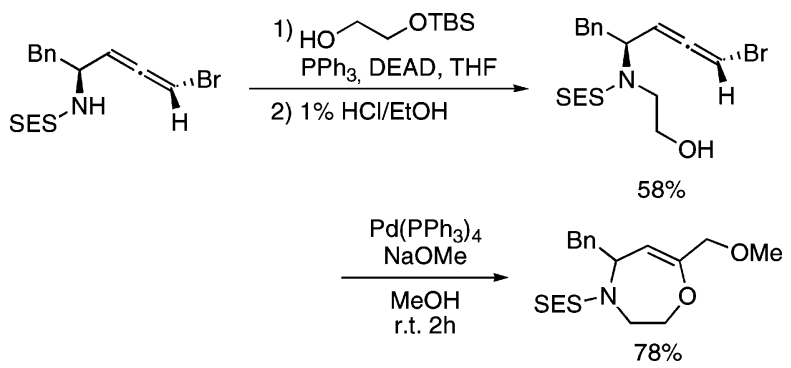

${ }^{a}$ Reprinted with permission from ref 118. Copyright 2004 American Chemical Society.

\subsection{Acylation Reactions}

Weinreb and co-workers ${ }^{101}$ described the acylation of a SES-protected amine during the total synthesis of Agelastatin (eq 22).
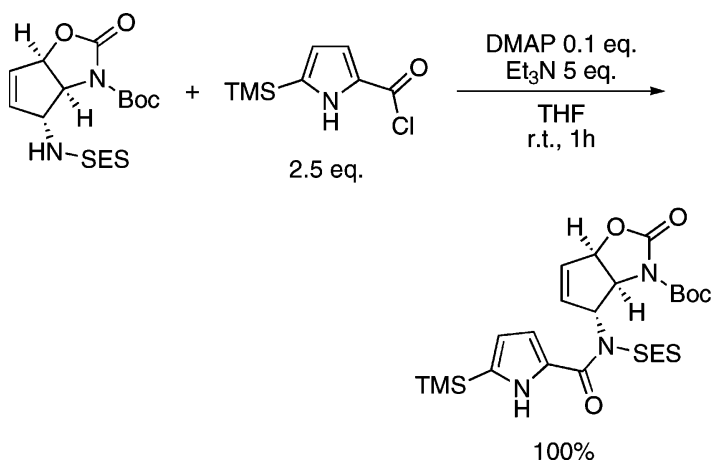

Other examples of acylations are related to carbamate formation such as $N$-(Boc)-SES sulfonamide, ${ }^{119}$ which was formed under mild conditions $\left(\mathrm{Boc}_{2} \mathrm{O}, \mathrm{DMAP}, \mathrm{Et}_{3} \mathrm{~N}\right)$. Surprisingly, the $N$-(Z)-SES sulfonamide ${ }^{41}$ is obtained under more drastic conditions (benzyl chloroformate in the presence of MeLi followed by $\mathrm{NaH})$. Cyclic carbamates were also synthesized from $\beta$-aminohydroxides under roughly the same conditions as those for $N$-(Boc)-SES sulfonamide (Scheme 40) and used in the total syntheses of Bactoboline $e^{58,63,120}$ and Luzopeptine. $^{121}$

\section{Limitations of SES Protection}

Whereas the tosylamide group (Ts) is inert against strong bases, the $\alpha$-protons of 2-(trimethylsilyl)ethanesulfonamide are sufficiently acidic to be abstracted by $n$-butyllithium or LDA. This feature, problematic in some reactions, can be
Scheme $40^{a}$

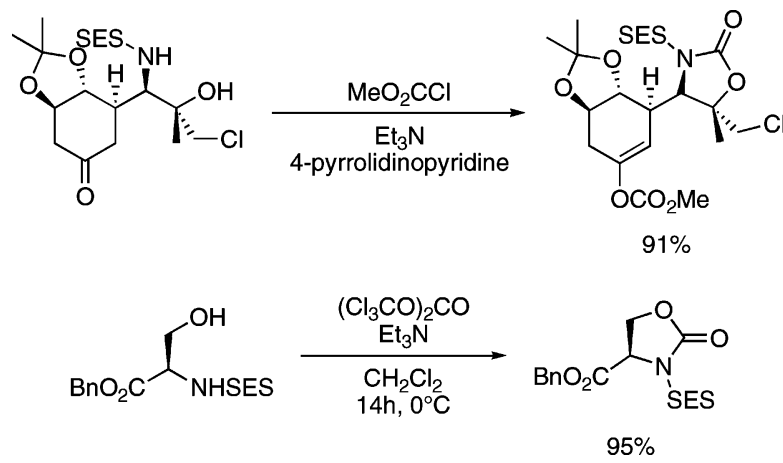

${ }^{a}$ Reprinted with permission from refs 120 and 121 . Copyright 1994 Elsevier and 1998 American Chemical Society.

used for the synthesis of the tert-butyl-[2-(trimethylsilyl)ethanesulfonyl]carbamate or $N$-(Boc)-SES sulfonamide ${ }^{38}$ (eq 23).

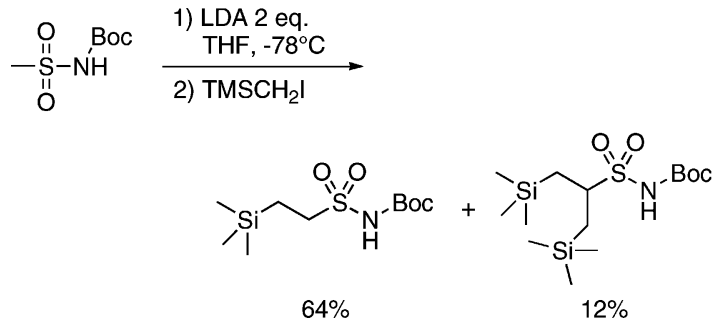

Limits of the SES protection arose during the reaction between phenyl(propynyl)iodonium triflate and the anion obtained by addition of $n$-butyllithium on sulfonamide (eq 24) providing dihydropyrrole. ${ }^{122}$

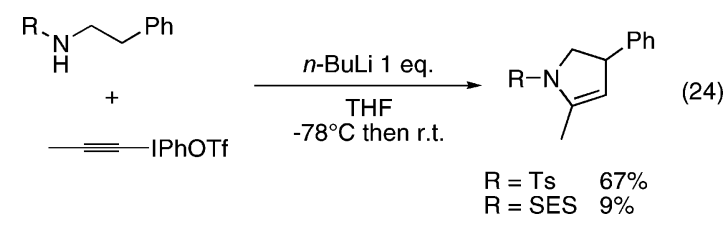

To circumvent this problem, a tosyl protection can be used and then replaced by the SES group ${ }^{123}$ (Scheme 41) provided that its deprotection is compatible with the existing functional groups.

However, at low temperature, LDA can be used to form, for example, the enolate of $N$-SES-Ala-OBn ${ }^{124}$ (Scheme 42).

\section{Deprotection of the SES Group}

\subsection{Fluoride Source/Deprotection Conditions}

Various conditions have been developed to deprotect the SES group. Nevertheless, two sources of fluoride are mainly used: cesium fluoride ( $\mathrm{CsF}$ ) in DMF and tetrabutylammonium fluoride (TBAF) in THF.

Other reagents are hydrofluoric acid, used during the final deprotection of depsipeptides by the group of Boger, ${ }^{11,31,125-127}$ and tris(dimethylamino)sulfonium difluorotrimethylsilicate $\left(\left(\mathrm{Me}_{2} \mathrm{~N}\right)_{3} \mathrm{~S}^{+} \mathrm{Me}_{3} \mathrm{SiF}_{2}{ }^{-}, \mathrm{TASF}\right)$, used during the deprotection of aziridines. ${ }^{85,91} \mathrm{TBAT}\left(n-\mathrm{Bu}_{4} \mathrm{~N}^{+} \mathrm{Ph}_{3} \mathrm{SiF}_{2}{ }^{-}\right)$, less hygroscopic than TASF, did not allow deprotection of the SES group ${ }^{77}$ (eq 12). Depending on the reagent and the reaction temperature, deprotection of the SES group can take from 15 min at room temperature ${ }^{48}$ to 3 days at $90{ }^{\circ} \mathrm{C} .{ }^{97}$ Finally, the 
Scheme $41^{a}$

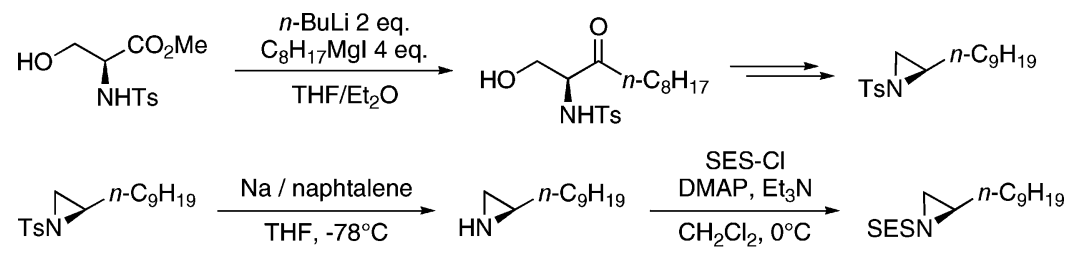

$56 \%$ (2 steps)

${ }^{a}$ Reprinted with permission from ref 123 . Copyright 2001 Georg Thieme Verlag.

Scheme $42^{a}$

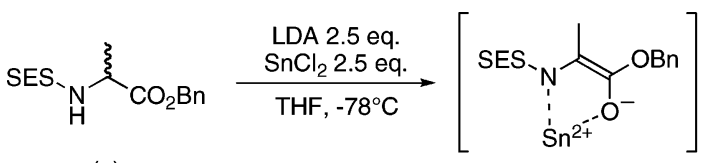

$( \pm)$

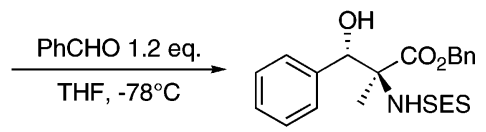

$( \pm)$-anti

$88 \%$ ds $=99 \%$

${ }^{a}$ Reprinted with permission from ref 124 . Copyright 1998 Wiley VCH Verlag.

Decicco group describes the concomitant cleavage of a Boc and a SES group on the same amine in refluxing $6 \mathrm{~N} \mathrm{HCl}^{46}$

\subsection{Orthogonality}

The orthogonality of the SES protecting group has been illustrated for the synthesis of Homocaldopentamine and Thermopentamine by Hesse and co-workers ${ }^{9,10,128}$ when a pentamine having five different protecting groups (Boc, allyl, TcBoc, azide, SES) is selectively deprotected (TFA, $\mathrm{Pd}\left(\mathrm{PPh}_{3}\right)_{4} / \mathrm{NDBMA}, \mathrm{Zn}_{\text {dust }} / \mathrm{AcOH}, \mathrm{PPh}_{3} / \mathrm{H}_{2} \mathrm{O}, \mathrm{CsF} / \mathrm{DMF}$, respectively) (Scheme 43). The SES protecting group is also orthogonal to the $\mathrm{Z}$ group.

\section{Scheme $43^{a}$}

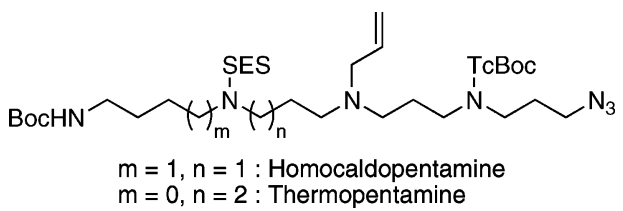

${ }^{a}$ Reprinted with permission from ref 128. Copyright 1998 Wiley VCH Verlag.

\subsection{Nonorthogonality}

The SES deprotection conditions also cleave silyl ethers such as a TBDPS-protected alcohol in the total synthesis of an oligosaccharide by Danishefsky and co-workers. ${ }^{95}$ This protecting group is also eliminated in the presence of fluoride ions without cleaving the SES group. ${ }^{12,115}$ The Fmoc group must be classified among the SES nonorthogonal protecting groups: Ueki and co-workers ${ }^{129,130}$ showed that the Fmoc group can be cleaved by TBAF under mild conditions. Boger and co-workers ${ }^{30-33}$ adapted this method to remove the Fmoc group in the synthesis of Ramoplanin (TBAF 8 equiv, $i$-PrOH 10 equiv, DMF, room temperature, $1 \mathrm{~h}$, sonication), which leaves no doubt about the Fmoc instability under the more drastic conditions used for the SES group.

\subsection{Problems Occurring during the Deprotection}

\subsubsection{Dehydrodesulfination/Aromatization}

Some SES-protected amines, having a SES-amino acid included in a cyclic structure, undergo a secondary reaction during the deprotection step (Scheme 44). In 1996 Bartlett and co-workers ${ }^{12}$ reported the first imine resulting from a deprotonation by fluoride ion followed by elimination of the SES group. In this case, Bartlett and co-workers were able to recycle this side product by sodium borohydride reduction to regenerate the chiral center with the same stereochemistry.

In the three other cases of this type of side reaction the cycle was already unsaturated and the reaction was followed by an aromatization step. In the first example, ${ }^{76}$ aromatization is directly obtained by elimination of the SES group, which can be performed with a weak base as well (eq 25). In the second case, ${ }^{56,82}$ aromatization involves isomerization of the imine intermediate into a pyrrole (Scheme 45). Better yields were obtained using a base. The reaction was also carried out on the same substrate with a Ts protecting group to generate the same product, but in this case the use of $\mathrm{NaOMe}$ did not allow elimination of the protecting group. Finally, didehydro derivatives of the pipecolic acid supported on a soluble polymer using a SES linker provided the corresponding pyridines after the dehydrodesulfination/aromatization sequence (Scheme 46). ${ }^{131}$

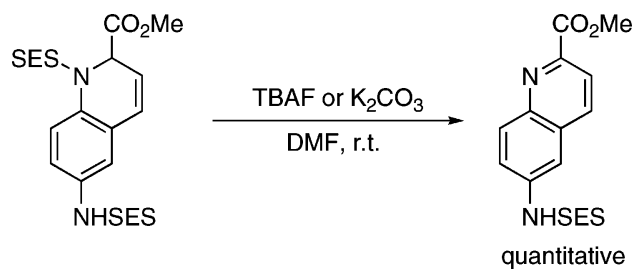

It is worth noting that this reaction can also be applied to tosyl derivatives. The resulting byproduct from this dehydrodesulfination reaction is the $p$-toluenesulfinic acid, the structure of which was confirmed by its conversion into the corresponding benzylic sulfone ${ }^{56}$ (Scheme 47).

\subsubsection{Primary Amine}

Several publications report on differences of reactivity during the deprotection step between a SES-protected primary amine and the same acylated molecule. Ward and co-workers ${ }^{132}$ synthesized a SES-aminoketone which was used as a model compound in the total synthesis of Actinobolin (Scheme 48). Deprotection of the $N$-acyl derivative is quickly performed under very mild conditions, whereas the monoprotected compound needs harsher conditions to remove the SES group. The same difference in the deprotection occurred during the synthesis of Agelastatin A. ${ }^{101}$ 
Scheme $44^{a}$

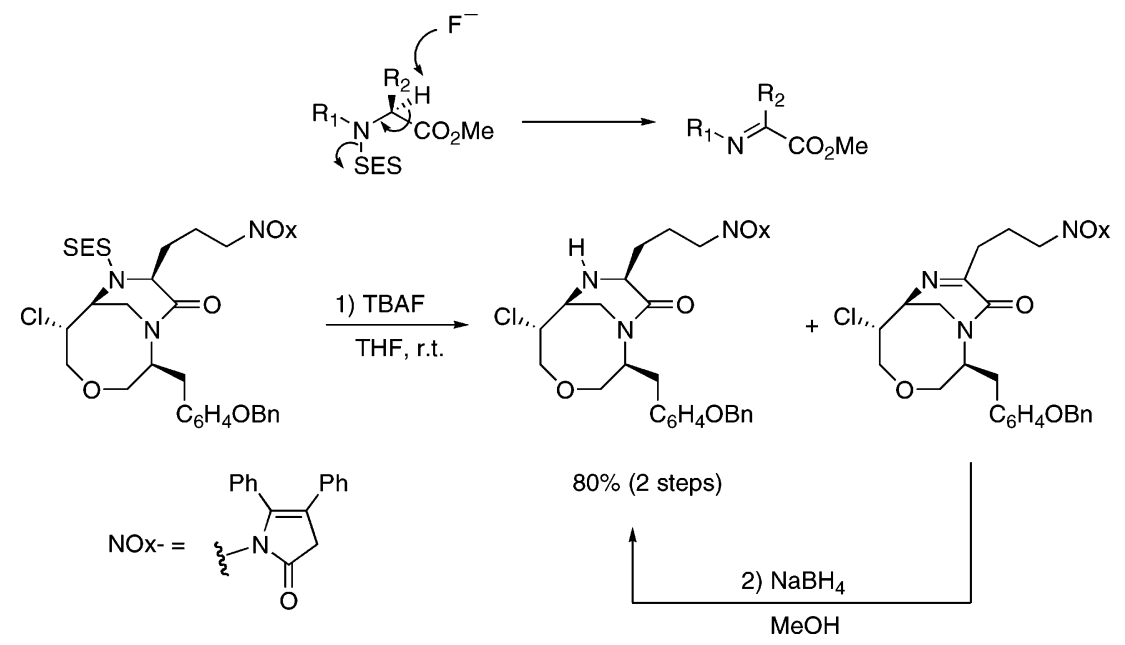

${ }^{a}$ Reprinted with permission from ref 12. Copyright 1996 American Chemical Society.

\section{Scheme $4^{a}$}

$\mathrm{MeO}_{2} \mathrm{C}$<smiles>COC(=O)C1=CCN(P)C1Br</smiles><smiles>C1CCCCC1</smiles><smiles></smiles><smiles>COC(=O)C1=CCCC1</smiles><smiles>CCCCCCC</smiles>

TBAF, THF
r.t., 24-36h

$\mathrm{NaOMe}$

$\mathrm{P}-=$ SES- or TSAr- $=\mathrm{Ph}-$, , $4-\mathrm{Me}^{-} \mathrm{C}_{6} \mathrm{H}_{4}^{-}, 4-\mathrm{Cl}_{-} \mathrm{C}_{6} \mathrm{H}_{4^{-}}$

$\mathrm{P}-=\mathrm{Ts}-\mathrm{Ar}-=\mathrm{Ph}-$

$t$-BuOK, DMF $\quad \mathrm{P}-=$ SES-

r.t., $2 \mathrm{~h}$

Ar- $=\mathrm{Ph}-$, 3-Me- $\mathrm{C}_{6} \mathrm{H}_{4}^{-}$, 3,5-diMe- $\mathrm{C}_{6} \mathrm{H}_{3}^{-}$, 3,5-diMeO- $\mathrm{C}_{6} \mathrm{H}_{3}^{-}, 4-\mathrm{MeO}_{2} \mathrm{C}-\mathrm{C}_{6} \mathrm{H}_{4}^{-}$,

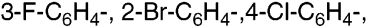
$2-\mathrm{I}_{6} \mathrm{H}_{4}$

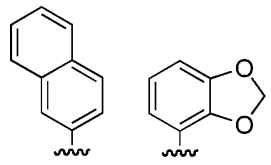

${ }^{a}$ Reprinted with permission from refs 56 and 82. Copyright 1998 and 2004 American Chemical Society.

\section{Scheme $46^{a}$}

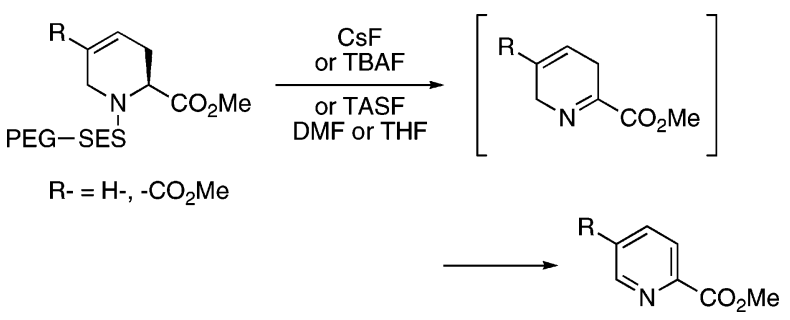

${ }^{a}$ Reprinted with permission from ref 131 . Copyright 2002 Wiley VCH Verlag.

Acylation of the SES-amine can even take place in situ during the deprotection step as described by Boger and coworkers $^{11}$ (Scheme 49). Instead of trapping the deprotected amine, $\mathrm{Boc}_{2} \mathrm{O}$ first acylates the SES-amine and activates its deprotection.

\section{5. "One-Pot" Deprotection and Electrophile Addition}

During the SES deprotection the formed amide can attack an electrophile in solution, leading to the corresponding substituted product. This strategy was developed by Hart and co-workers ${ }^{35,116}$ through an intramolecular process for the

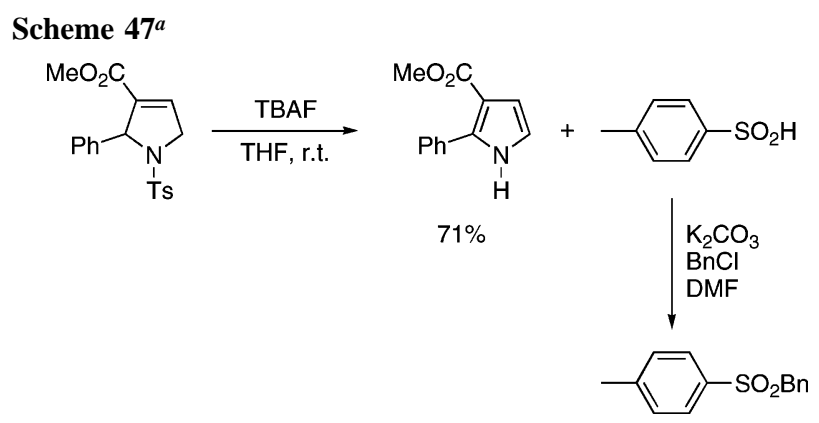

${ }^{a}$ Reprinted with permission from ref 56. Copyright 1998 American Chemical Society.

Scheme $48^{a}$
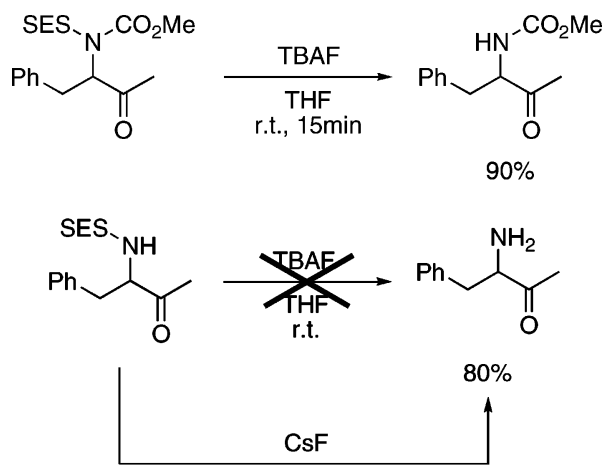

$\mathrm{DMF}, 95^{\circ} \mathrm{C}$

${ }^{a}$ Reprinted with permission from ref 132. Copyright 1996 American Chemical Society.

Scheme $49^{a}$

\begin{tabular}{|c|c|c|c|c|}
\hline \multirow[t]{2}{*}{ SES、 } & & CsF & \\
\hline & $\mathrm{CO}_{2} \mathrm{Me}$ & DMF & & $\mathrm{CO}_{2} \mathrm{Me}$ \\
\hline $\mathrm{Boc}_{2} \mathrm{O}$ & $\mathrm{T}\left({ }^{\circ} \mathrm{C}\right)$ & $\mathrm{t}(\mathrm{h})$ & $\mathrm{R}$ & Yield (\%) \\
\hline- & 95 & 12 & $\mathrm{H}$ & 40 \\
\hline $10 \mathrm{eq}$. & 50 & 6 & Boc & 96 \\
\hline
\end{tabular}

${ }^{a}$ Reprinted with permission from ref 11. Copyright 1996 American Chemical Society.

preparation of a Manzamine A model and intermediate compounds. In this synthesis the amide generated from the SES deprotection attacks the cyclohexadienone to produce the corresponding perhydroindole with a diastereoselectivity depending on the size of the cycle containing 


\section{Scheme 50}

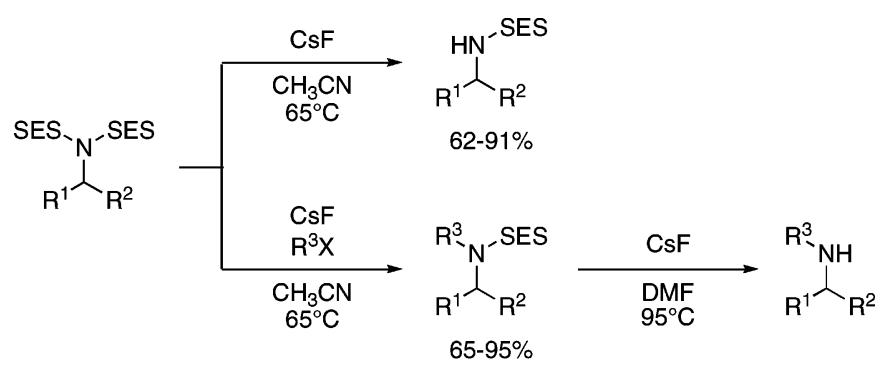

\begin{tabular}{|c|c|c|c|c|}
\hline \multirow{2}{*}{$\begin{array}{l}\text { Bis-SES-protected } \\
\text { amine }\end{array}$} & \multirow{2}{*}{$\begin{array}{c}\text { Monodeprotection } \\
\text { Yield (\%) }\end{array}$} & \multicolumn{2}{|c|}{ Monodeprotection $/ N$-alkylation } & \multirow{2}{*}{$\begin{array}{l}\text { Deprotection } \\
\text { Yield (\%) }\end{array}$} \\
\hline & & $\mathrm{R}^{3} \mathrm{X}$ & Yield (\%) & \\
\hline $\mathrm{NSES}_{2}$ & 73 & $\mathrm{BnBr}$ & 95 & - \\
\hline $\mathrm{NSES}_{2}$ & 71 & - & - & - \\
\hline $\mathrm{ES}_{2}$ & 83 & - & - & - \\
\hline $\mathrm{NSES}_{2}$ & 64 & $\mathrm{BnBr}$ & 75 & 75 \\
\hline $\mathrm{NSES}_{2}$ & 62 & $\mathrm{BuI}$ & 65 & - \\
\hline & 91 & - & - & - \\
\hline$p-\mathrm{MeO}-\mathrm{C}_{6} \mathrm{H}_{4} \widehat{\mathrm{NSES}_{2}}$ & - & Allyl bromide & 93 & - \\
\hline
\end{tabular}

${ }^{a}$ Reprinted with permission from ref 51. Copyright 2003 American Chemical Society.

\section{Scheme 51}
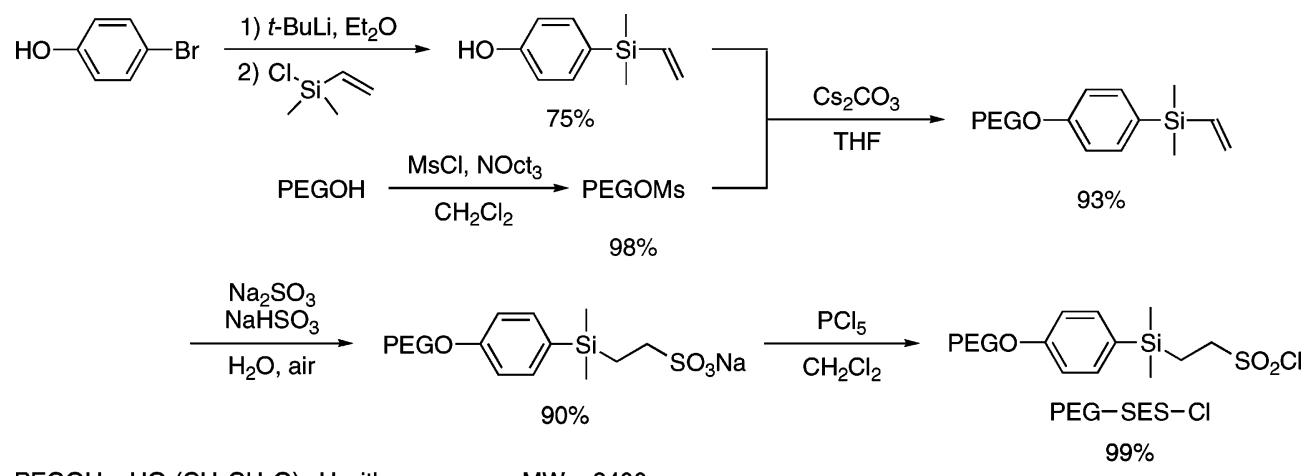

$\mathrm{PEGOH}=\mathrm{HO}-\left(\mathrm{CH}_{2} \mathrm{CH}_{2} \mathrm{O}\right)_{n}-\mathrm{H}$ with an average $\mathrm{MW}=3400$

${ }^{a}$ Reprinted with permission from ref 131. Copyright 2002 Wiley VCH Verlag.

the initially protected amine (eq 26).

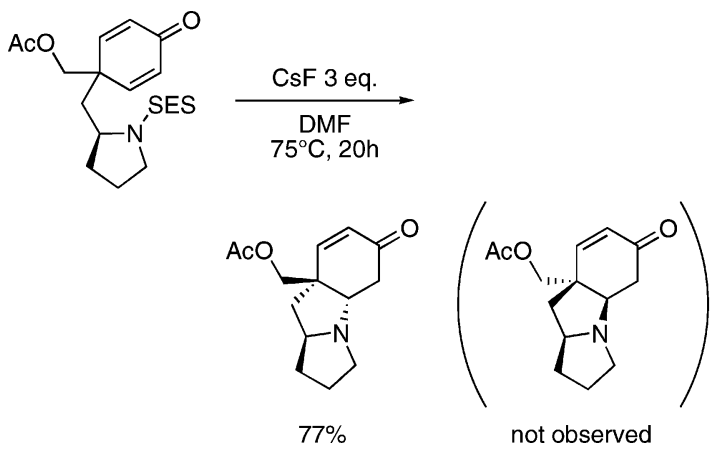

An intermolecular version was described by Weinreb and co-workers $^{51}$ with a bis-SES-protected amine. The one-pot monodeprotection $/ N$-alkylation can directly provide the mono-SES secondary amine derivative (Scheme 50).

\section{SES Protection on Polymeric Support}

SES protecting groups supported on a soluble poly(ethylene glycol) polymer have been developed. ${ }^{131,133}$ Synthesis of the PEG-supported SES group has been approached on the basis of the solution chemistry developed by Weinreb. Two types of SES linkers were developed.

In the first one, a phenyl ring was selected to connect the oxygen of the polymer to the silicon atom ${ }^{131}$ (Scheme 51). This supported PEG-SES linker was used in the synthesis of several cyclic amino acids by ring-closing metathesis (RCM) of various supported $N$-alkylated allylglycines (Scheme 52). The synthesis started by anchoring the L-allylglycine 
Scheme $52^{a}$

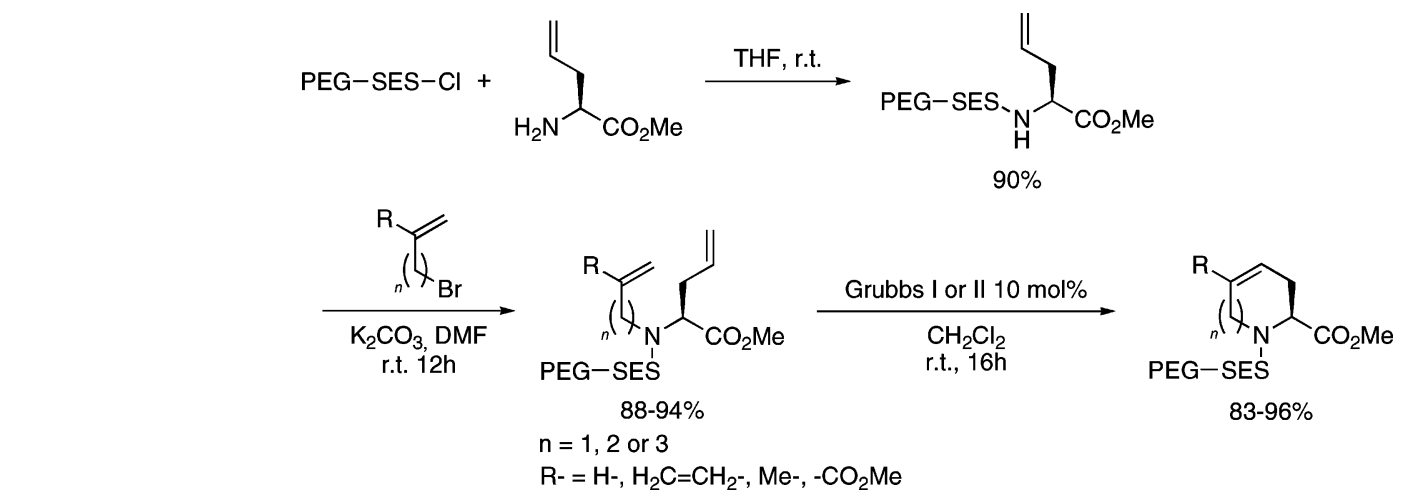

${ }^{a}$ Reprinted with permission from ref 131. Copyright 2002 Wiley VCH Verlag.

Scheme 53
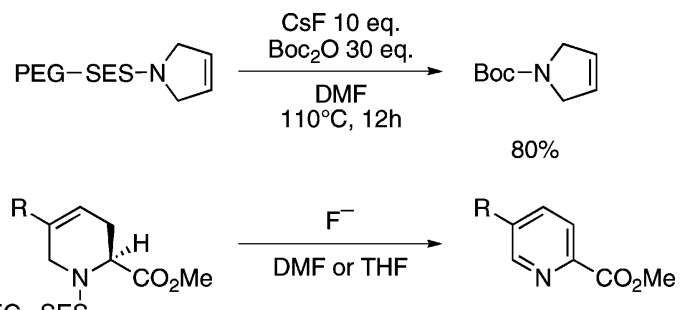

PEG-SES

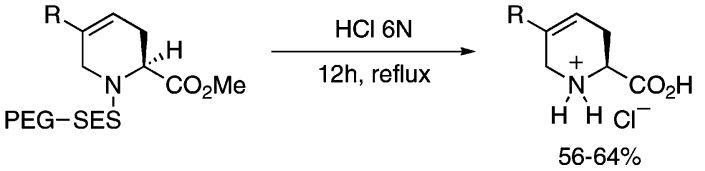

${ }^{a}$ Reprinted with permission from ref 131 . Copyright 2002 Wiley VCH Verlag.

methyl ester to $\mathrm{PEG}-\mathrm{SES}-\mathrm{Cl}$ to provide the corresponding supported sulfonamide. This compound was then substituted with various alkylating agents and subjected to RCM to obtain substituted cyclic amino acids of various ring sizes.
Deprotection of the PEG-SES was first performed on a supported pyrroline, and the resulting cleaved product gave a good yield under the traditional deprotection conditions (Scheme 53). When the didehydro derivatives of pipecolic acid were submitted to the same cleavage conditions, only a small quantity of the expected products was obtained. Only the corresponding pyridines were obtained despite the use of fluoride (CsF, TBAF, TASF). This phenomenon is related to the mechanism of dehydrodesulfination/aromatization described in section 6.4. Even the deprotection of seven- and eight-membered cyclic aminoesters, yet not susceptible to aromatization, provided only complicated mixtures from which no major compounds could be isolated. The supported aminoesters were thus cleaved by hydrolysis in refluxing 6 $\mathrm{N} \mathrm{HCl}$ to yield the corresponding fully deprotected amino acids.

However, the main drawback of this supported SES protection is its sensitivity to acidic medium. Indeed, some phenyl-silicon-type linkers ${ }^{134,135}$ have already been described for the supported synthesis of arylic compounds, and the aryl-silicon bond is cleaved in acidic medium at the end of the synthesis.

\section{Scheme 54}
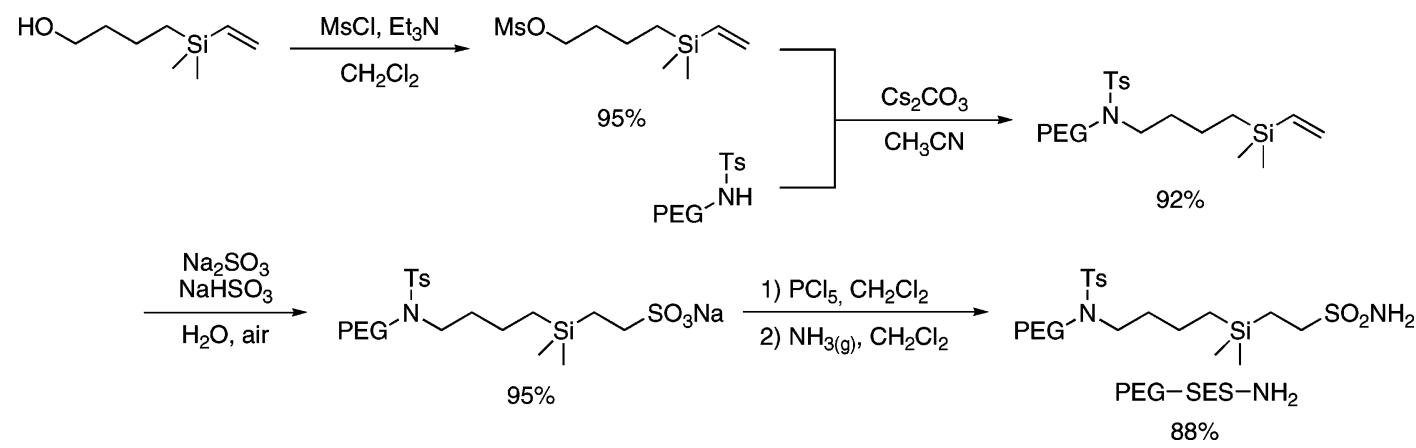

${ }^{a}$ Reprinted with permission from ref 133. Copyright 2004 American Chemical Society.

\section{Scheme $5^{a}$}

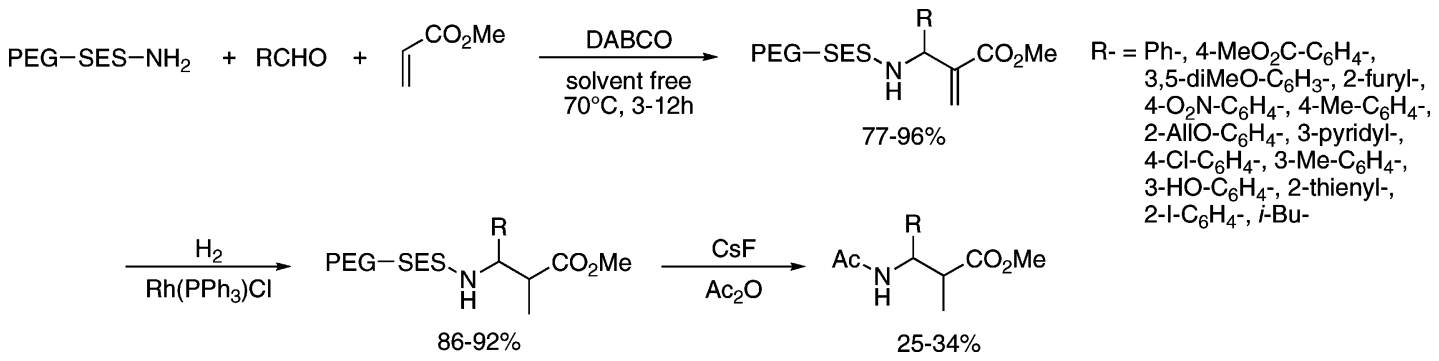

${ }^{a}$ Reprinted with permission from ref 133. Copyright 2004 American Chemical Society. 
Another PEG-supported SES-type linker has been synthesized and then transformed into the corresponding sulfonamide $^{133}$ (Scheme 54). This sulfonamide was then used in a supported version of the three-component aza-BaylisHilman reaction (see section 3.2.7) to provide PEG-supported $\beta$-aminoesters under classical conditions ${ }^{133}$ or microwave activation. ${ }^{136}$ The PEG-supported $\beta$-aminoesters were submitted to a hydrogenation/cleavage sequence. ${ }^{136}$ The hydrogenation reaction was performed with $\mathrm{H}_{2}$ in the presence of Wilkinson's catalyst to yield the hydrogenated compounds with excellent conversion. Release from the polymer support was performed by action of fluoride ions, followed by trapping with acetic anhydride, to generate the acetylated aminoesters in rather low yields (Scheme 55).

\section{Conclusion}

The SES group is an amine protecting group already described in several types of synthesis. Beyond the simple amine protection, the reagents derived from $\mathrm{SES}-\mathrm{NH}_{2}$ give access to a large variety of amino compounds by direct introduction of SES - sulfonamide into a substrate. Stability, orthogonality, and mild conditions of deprotection, as well as activating properties, make the use of the SES protecting group in synthesis very attractive, competitive with the tosyl group.

\section{Abbreviations}

$\begin{array}{ll}\text { acac } & \text { acetylacetonate } \\ \text { Boc } & \text { tert-butyloxycarbonyl } \\ \mathrm{Boc}_{2} \mathrm{O} & \text { di-tert-butyl dicarbonate } \\ \text { BOP-Cl } & \text { bis(2-oxo-3-oxazolidinyl)phosphinic chloride } \\ \text { CSA } & \text { 10-camphorsulfonic acid } \\ \text { DABCO } & \text { 1,4-diazabicyclo[2.2.2]octane } \\ \text { dba } & \text { dibenzylideneacetone } \\ \text { DEAD } & \text { diethyl azodicarboxylate } \\ \text { DIEA } & \text { diisopropylethylamine } \\ \text { DMAP } & \text { 4-(N,N-dimethylamino)pyridine } \\ \text { Fmoc } & \text { 9-fluorenylmethoxycarbonyl } \\ \text { HMPA } & \text { hexamethylphosphoramide } \\ \text { KHMDS } & \text { potassium hexamethyldisilazide } \\ \text { LDA } & \text { lithium diisopropylamide } \\ \text { LiHMDS } & \text { lithium hexamethyldisilazide } \\ \text { LTMP } & \text { lithium 2,2,6,6-tetramethylpiperidine } \\ \text { MOM } & \text { methoxymethyl } \\ \text { Ms } & \text { mesyl } \\ \text { MS } & \text { molecular sieves } \\ \text { NDBMA } & N, N^{\prime} \text {-dimethylbarbituric acid } \\ \text { NMM } & N \text {-methylmorpholine } \\ \text { PCC } & \text { pyridinium chlorochromate } \\ \text { PEG } & \text { poly(ethylene glycol) } \\ \text { Phth } & \text { phthaloyl } \\ \text { PTC } & \text { phase-transfer catalyst } \\ \text { SEM } & {[2 \text {-(trimethylsilyl)ethoxy]methyl }} \\ \text { sym-coll } & 2,4,6 \text {-trimethylpyridine } \\ \text { TASF } & \text { tris(dimethylamino)sulfonium difluorotrimethylsilicate } \\ \text { TBAF } & \text { tetrabutylammonium fluoride } \\ \text { TBAT } & \text { tetrabutylammonium triphenyldifluorosilicate } \\ \text { TBDPS } & \text { tert-butyldiphenylsilyl } \\ \text { TcBoc } & \text { trichloro-tert-butyloxycarbonyl } \\ \text { TFA } & \text { trifluoroacetic acid } \\ \text { THP } & \text { tetrahydropyranyl } \\ \text { THT } & \text { tetrahydrothiophene } \\ \text { TMSCl } & \text { trimethylsilyl chloride } \\ \text { Ts } & \text { tosyl } \\ \text { Z } & \text { benzyloxycarbonyl } \\ & \end{array}$

\section{References}

(1) Weinreb, S. M.; Demko, D. M.; Lessen, T. A.; Demers, J. P. Tetrahedron Lett. 1986, 27, 2099.

(2) 2-(Trimethylsilyl)ethanesulfonamide ( $\mathrm{SES}-\mathrm{NR}_{2}$ ). In Protective Groups in Organic Synthesis, 3rd ed.; Greene, T. W., Wuts, P. G. M., Eds. Wiley: New York, 1999; p 612.

(3) Weinreb, S. M.; Ralbovsky, J. L. $\beta$-(Trimethylsilyl)ethanesulfonyl Chloride. In Handbook of Reagents for Organic Synthesis: Activating Agents and Protecting Groups; Pearson, A. J., Roush, W. J., Eds.; Wiley: Chichester, 1999; p 425.

(4) Kocienski, P. J. $\beta$-(Trimethylsilyl)ethanesulfonyl (SES) Derivatives. In Protecting Groups; Corrected ed.; Enders, D., Noyori, R., Trost, B. M., Eds.; Thieme: Stuttgart; New York, 2000; p 215.

(5) Chambert, S.; Désiré, J.; Décout, J.-L. Synthesis 2002, 2319.

(6) Weinreb, S. M.; Chase, C. E.; Wipf, P.; Venkatraman, S. Org. Synth. 1998, 75, 161.

(7) Huang, J.; Widlanski, T. S. Tetrahedron Lett. 1992, 33, 2657.

(8) Matzanke, N.; Gregg, R. J.; Weinreb, S. M.; Parvez, M. J. Org. Chem. 1997, 62, 1920.

(9) Pak, J. K.; Guggisberg, A.; Hesse, M. Tetrahedron 1998, 54, 8035.

(10) Pak, J. K.; Hesse, M. J. Org. Chem. 1998, 63, 8200.

(11) Boger, D. L.; Chen, J.-H.; Saionz, K. W. J. Am. Chem. Soc. 1996, $118,1629$.

(12) Kozlowski, M. C.; Bartlett, P. A. J. Org. Chem. 1996, 61, 7681.

(13) Hoye, R. C.; Richman, J. E.; Dantas, G. A.; Lightbourne, M. F.; Shinneman, L. S. J. Org. Chem. 2001, 66, 2722.

(14) Bélanger, G.; Hong, F.-T.; Overman, L. E.; Rogers, B. N.; Tellew, J. E.; Trenkle, W. C. J. Org. Chem. 2002, 67, 7880.

(15) Wipf, P.; Venkatraman, S.; Miller, C. P. Tetrahedron Lett. 1995 36, 3639.

(16) Wipf, P.; Venkatraman, S. J. Org. Chem. 1995, 60, 7224.

(17) Wipf, P.; Venkatraman, S. Synlett 1997, 1.

(18) Miller, A. D.; Leeper, F. J.; Battersby, A. R. J. Chem. Soc., Perkin Trans. 1 1989, 1943.

(19) Pichon, C.; Scott, A. I. Recl. Trav. Chim. Pays-Bas 1996, 115, 1.

(20) Kajimoto, T.; Liu, K. K.-C.; Pederson, R. L.; Zhong, Z.; Ichikawa, Y.; Porco, J. A., Jr.; Wong, C.-H. J. Am. Chem. Soc. 1991, 113, 6187

(21) Turner, R. M.; Lindell, S. D.; Ley, S. V. J. Org. Chem. 1991, 56, 5739

(22) Moreno, O. A.; Kishi, Y. J. Am. Chem. Soc. 1996, 118, 8180.

(23) Moreno, O. A.; Kishi, Y. Bioorg. Med. Chem. 1998, 6, 1243.

(24) Meegalla, S. K.; Stevens, G. J.; McQueen, C. A.; Chen, A. Y.; Yu, C.; Liu, L. F.; Barrows, L. R.; LaVoie, E. J. J. Med. Chem. 1994 37, 3434.

(25) Nouvet, A.; Binard, M.; Lamaty, F.; Lazaro, R. Lett. Pept. Sci. 1999, $6,239$.

(26) Nouvet, A.; Binard, M.; Lamaty, F.; Martinez, J.; Lazaro, R. Tetrahedron 1999, 55, 4685.

(27) Boger, D. L.; Chen, J.-H. J. Am. Chem. Soc. 1993, 115, 11624.

(28) Boger, D. L.; Saionz, K. W. Bioorg. Med. Chem. 1999, 7, 315.

(29) Boger, D. L.; Zhou, J. J. Am. Chem. Soc. 1993, 115, 11426.

(30) Jiang, W.; Wanner, J.; Lee, R. J.; Bounaud, P.-Y.; Boger, D. L. J. Am. Chem. Soc. 2002, 124, 5288.

(31) Jiang, W.; Wanner, J.; Lee, R. J.; Bounaud, P.-Y.; Boger, D. L. J. Am. Chem. Soc. 2003, 125, 1877.

(32) Shin, D.; Rew, Y.; Boger, D. L. Proc. Natl. Acad. Sci. U.S.A. 2004 101, 11977.

(33) Rew, Y.; Shin, D.; Hwang, I.; Boger, D. L. J. Am. Chem. Soc. 2004, 126, 1041.

(34) Desai, P.; Pfeiffer, S. S.; Boger, D. L. Org. Lett. 2003, 5, 5047.

(35) Bland, D.; Hart, D. J.; Lacoutière, S. Tetrahedron 1997, 53, 8871

(36) Goodenough, K. M.; Raubo, P.; Harrity, J. P. A. Org. Lett. 2005, 7, 2993

(37) Campbell, J. A.; Hart, D. J. Tetrahedron Lett. 1992, 33, 6247.

(38) Campbell, J. A.; Hart, D. J. J. Org. Chem. 1993, 58, 2900.

(39) Li, S.; Kosemura, S.; Yamamura, S. Tetrahedron Lett. 1994, 35, 8217.

(40) Grillot, A.-L.; Hart, D. J. Heterocycles 1994, 39, 435.

(41) Grillot, A.-L.; Hart, D. J. Tetrahedron 1995, 51, 11377.

(42) Li, S.; Ohba, S.; Kosemura, S.; Yamamura, S. Tetrahedron Lett. 1996 37, 7365 .

(43) Li, S.; Yamamura, S. Tetrahedron Lett. 1998, 39, 2597.

(44) Li, S.; Kosemura, S.; Yamamura, S. Tetrahedron 1998, 54, 6661.

(45) Li, S.; Yamamura, S. Tetrahedron 1998, 54, 8691.

(46) Decicco, C. P.; Grover, P. Synlett 1997, 529.

(47) Campbell, J. A.; Rapoport, H. J. Org. Chem. 1996, 61, 6313.

(48) Gao, Y.; Lane-Bell, P.; Vederas, J. C. J. Org. Chem. 1998, 63, 2133.

(49) Wiśniewski, K.; Kołdziejczyk, A. S.; Falkiewicz, B. J. Pept. Sci. 1998, 4,1 .

(50) Lee, E.; Jeong, E. J.; Min, S. J.; Hong, S.; Lim, J.; Kim, S. K.; Kim, H. J.; Choi, B. G.; Koo, K. C. Org. Lett. 2000, 2, 2169. 
(51) Dastrup, D. M.; VanBrunt, M. P.; Weinreb, S. M. J. Org. Chem. 2003, 68, 4112.

(52) Chemla, F.; Hebbe, V.; Normant, J.-F. Synthesis 2000, 75.

(53) McKay, W. R.; Proctor, G. R. J. Chem. Soc., Perkin Trans. 1 1981, 2435.

(54) Aggarwal, V. K.; Thompson, A.; Jones, R. V. H.; Standen, M. C. H. J. Org. Chem. 1996, 61, 8368 .

(55) Aggarwal, V. K.; Ferrara, M.; O’Brien, C. J.; Thompson, A.; Jones, R. V. H.; Fieldhouse, R. J. Chem. Soc., Perkin Trans. 1 2001, 1635.

(56) Xu, Z.; Lu, X. J. Org. Chem. 1998, 63, 5031.

(57) Kresze, G.; Wucherpfennig, W. Angew. Chem., Int. Ed. Engl. 1967, $6,149$.

(58) Garigipati, R. S.; Tschaen, D. M.; Weinreb, S. M. J. Am. Chem. Soc. 1990, 112, 3475 .

(59) Schleusner, M.; Gais, H.-J.; Koep, S.; Raabe, G. J. Am. Chem. Soc. 2002, 124, 7789 .

(60) Kim, Y. H.; Shin, J. M. Tetrahedron Lett. 1985, 26, 3821.

(61) Sisko, J.; Weinreb, S. M. Tetrahedron Lett. 1989, 30, 3037.

(62) Sisko, J.; Weinreb, S. M. J. Org. Chem. 1990, 55, 393.

(63) Garigipati, R. S.; Weinreb, S. M. J. Org. Chem. 1988, 53, 4143.

(64) Artman, G. D., III; Bartolozzi, A.; Franck, R. W.; Weinreb, S. M. Synlett 2001, 232.

(65) Schwan, A. L.; Dufault, R. Tetrahedron Lett. 1992, 33, 3973.

(66) Schwan, A. L.; Brillon, D.; Dufault, R. Can. J. Chem. 1994, 72, 325 .

(67) Fujihara, H.; Nagai, K.; Tomioka, K. J. Am. Chem. Soc. 2000, 122, 12055.

(68) Wang, C.-J.; Shi, M. J. Org. Chem. 2003, 68, 6229.

(69) Ferraris, D.; Young, B.; Dudding, T.; Drury, W. J., III; Lectka, T. Tetrahedron 1999, 55, 8869 .

(70) Ferraris, D.; Dudding, T.; Young, B.; Drury, W. J., III; Lectka, T. J. Org. Chem. 1999, 64, 2168.

(71) Nemoto, H.; Kubota, Y.; Sasaki, N.; Yamamoto, Y. Synlett 1993, 465

(72) Li, B.; Franck, R. W.; Capozzi, G.; Menichetti, S.; Nativi, C. Org. Lett. 1999, 1, 111.

(73) Bartolozzi, A.; Li, B.; Franck, R. W. Bioorg. Med. Chem. 2003, 11, 3021.

(74) Diep, V.; Dannenberg, J. J.; Franck, R. W. J. Org. Chem. 2003, 68,

(75) Zhu, X.-F.; Henry, C. E.; Kwon, O. Tetrahedron 2005, 61, 6276.

(76) Parker, K. A.; Mindt, T. L. Org. Lett. 2002, 4, 4265.

(77) Aggarwal, V. K.; Ferrara, M. Org. Lett. 2000, 2, 4107.

(78) Aggarwal, V. K.; Stenson, R. A.; Jones, R. V. H.; Fieldhouse, R.; Blacker, J. Tetrahedron Lett. 2001, 42, 1587.

(79) Aggarwal, V. K.; Alonso, E.; Fang, G.; Ferrara, M.; Hynd, G.; Porcelloni, M. Angew. Chem., Int. Ed. 2001, 40, 1433.

(80) Aggarwal, V. K.; Alonso, E.; Ferrara, M.; Spey, S. E. J. Org. Chem. 2002, 67, 2335

(81) Aggarwal, V. K.; Vasse, J.-L. Org. Lett. 2003, 5, 3987.

(82) Declerck, V.; Ribière, P.; Martinez, J.; Lamaty, F. J. Org. Chem. 2004, 69, 8372 .

(83) Shi, M.; Xu, Y.-M.; Shi, Y.-L. Chem. Eur. J. 2005, 11, 1794.

(84) Shi, M.; Chen, L.-H.; Li, C.-Q. J. Am. Chem. Soc. 2005, 127, 3790.

(85) Dauban, P.; Dodd, R. H. J. Org. Chem. 1999, 64, 5304.

(86) Di Chenna, P. H.; Dauban, P.; Ghini, A.; Burton, G.; Dodd, R. H. Tetrahedron Lett. 2000, 41, 7041.

(87) Di Chenna, P. H.; Dauban, P.; Ghini, A.; Baggio, R.; Garland, M. T.; Burton, G.; Dodd, R. H. Tetrahedron 2003, 59, 1009.

(88) Leman, L.; Sanière, L.; Dauban, P.; Dodd, R. H. Arkivoc 2003, 126.

(89) Sanière, L.; Leman, L.; Bourguignon, J.-J.; Dauban, P.; Dodd, R. H. Tetrahedron 2004, 60, 5889 .

(90) Dauban, P.; Sanière, L.; Tarrade, A.; Dodd, R. H. J. Am. Chem. Soc. 2001, 123, 7707

(91) Nishimura, M.; Minakata, S.; Takahashi, T.; Oderaotoshi, Y.; Komatsu, M. J. Org. Chem. 2002, 67, 2101

(92) Cren, S.; Kinahan, T. C.; Skinner, C. L.; Tye, H. Tetrahedron Lett. 2002, 43, 2749.

(93) Tye, H.; Skinner, C. L. Helv. Chim. Acta 2002, 85, 3272

(94) Danishefsky, S. J.; Koseki, K.; Griffith, D. A.; Gervay, J.; Peterson, J. M.; McDonald, F. E.; Oriyama, T. J. Am. Chem. Soc. 1992, 114, 8331.
(95) Danishefsky, S. J.; Gervay, J.; Peterson, J. M.; McDonald, F. E.; Koseki, K.; Griffith, D. A.; Oriyama, T.; Marsden, S. P. J. Am. Chem Soc. 1995, 117, 1940.

(96) Griffith, D. A.; Danishefsky, S. J. J. Am. Chem. Soc. 1996, 118, 9526

(97) Ritzeler, O.; Hennig, L.; Findeisen, M.; Welzel, P.; Mueller, D. Tetrahedron 1997, 53, 1665

(98) Wang, Z.-G.; Zhang, X.; Visser, M.; Live, D.; Zatorski, A.; Iserloh, U.; Lloyd, K. O.; Danishefsky, S. J. Angew. Chem., Int. Ed. 2001, 40, 1728.

(99) Ritzeler, O.; Hennig, L.; Findeisen, M.; Welzel, P.; Mueller, D.; Markus, A.; van Heijenoort, J. Tetrahedron 1997, 53, 1675.

(100) Owens, J. M.; Yeung, B. K. S.; Hill, D. C.; Petillo, P. A. J. Org. Chem. 2001, 66, 1484

(101) Stien, D.; Anderson, G. T.; Chase, C. E.; Koh, Y.-h.; Weinreb, S M. J. Am. Chem. Soc. 1999, 121, 9574.

(102) Anderson, G. T.; Chase, C. E.; Koh, Y.-h.; Stien, D.; Weinreb, S. M.; Shang, M. J. Org. Chem. 1998, 63, 7594.

(103) Domostoj, M. M.; Irving, E.; Scheinmann, F.; Hale, K. J. Org. Lett. 2004, 6, 2615.

(104) Hale, K. J.; Domostoj, M. M.; Tocher, D. A.; Irving, E.; Scheinmann, F. Org. Lett. 2003, 5, 2927.

(105) Reggelin, M.; Weinberger, H.; Spohr, V. Adv. Synth. Catal. 2004, $346,1295$.

(106) Katukojvala, S.; Barlett, K. N.; Lotesta, S. D.; Williams, L. J. J. Am. Chem. Soc. 2004, 126, 15348.

(107) Cho, S. H.; Yoo, E. J.; Bae, I.; Chang, S. J. Am. Chem. Soc. 2005, 127, 16046.

(108) Mitsunobu, O. Synthesis 1981, 1.

(109) Bordwell, F. G. Acc. Chem. Res. 1988, 21, 456.

(110) Zhang, H.-Y.; Yu, J.-Q.; Bruice, T. C. Tetrahedron 1994, 50, 11339.

(111) Zhang, H.-Y.; Bruice, T. C. Inorg. Chim. Acta 1996, 247, 195.

(112) Parker, L. L.; Gowans, N. D.; Jones, S. W.; Robins, D. J. Tetrahedron 2003, 59, 10165.

(113) Masllorens, J.; Moreno-Mañas, M.; Roglans, A. Tetrahedron 2005, $61,10105$.

(114) Varray, S.; Lazaro, R.; Martinez, J.; Lamaty, F. Organometallics 2003, 22, 2426.

(115) Li, S.; Yamamura, S.; Hosomi, H.; Ohba, S. Tetrahedron Lett. 1998 , 39, 2601.

(116) Bland, D.; Chambournier, G.; Dragan, V.; Hart, D. J. Tetrahedron 1999, 55, 8953.

(117) Kim, S. K.; Jacobsen, E. N. Angew. Chem., Int. Ed. 2004, 43, 3952

(118) Ohno, H.; Hamaguchi, H.; Ohata, M.; Kosaka, S.; Tanaka, T. J. Am. Chem. Soc. 2004, 126, 8744

(119) Neustadt, B. R. Tetrahedron Lett. 1994, 35, 379.

(120) Ward, D. E.; Gai, Y.; Kaller, B. F. Tetrahedron Lett. 1994, 35, 3485.

(121) Boger, D. L.; Schüle, G. J. Org. Chem. 1998, 63, 6421.

(122) Feldman, K. S.; Bruendl, M. M.; Schildknegt, K.; Bohnstedt, A. C. J. Org. Chem. 1996, 61, 5440.

(123) Caldwell, J. J.; Craig, D.; East, S. P. Synlett 2001, 1602.

(124) Grandel, R.; Kazmaier, U. Eur. J. Org. Chem. 1998, 409, 9.

(125) Boger, D. L.; Ledeboer, M. W.; Kume, M. J. Am. Chem. Soc. 1999, $121,1098$.

(126) Boger, D. L.; Ledeboer, M. W.; Kume, M.; Jin, Q. Angew. Chem., Int. Ed. Engl. 1999, 38, 2424.

(127) Boger, D. L.; Ledeboer, M. W.; Kume, M.; Searcey, M.; Jin, Q. J. Am. Chem. Soc. 1999, 121, 11375.

(128) Pak, J. K.; Hesse, M. Helv. Chim. Acta 1998, 81, 2300.

(129) Ueki, M.; Amemiya, M. Tetrahedron Lett. 1987, 28, 6617.

(130) Ueki, M.; Nishigaki, N.; Aoki, H.; Tsurusaki, T.; Katoh, T. Chem. Lett. 1993, 721.

(131) Varray, S.; Lazaro, R.; Martinez, J.; Lamaty, F. Eur. J. Org. Chem. 2002, 2308

(132) Ward, D. E.; Gai, Y.; Kaller, B. F. J. Org. Chem. 1996, 61, 5498

(133) Ribière, P.; Enjalbal, C.; Aubagnac, J.-L.; Yadav-Bhatnagar, N.; Martinez, J.; Lamaty, F. J. Comb. Chem. 2004, 6, 464.

(134) Plunkett, M. J.; Ellman, J. A. J. Org. Chem. 1995, 60, 6006.

(135) Newlander, K. A.; Chenera, B.; Veber, D. F.; Yim, N. C. F.; Moore, M. L. J. Org. Chem. 1997, 62, 6726.

(136) Ribière, P.; Yadav-Bhatnagar, N.; Martinez, J.; Lamaty, F. QSAR Comb. Sci. 2004, 23, 911.

CR0300587 